\title{
Analysis of ORP2-knockout hepatocytes uncovers a novel function in actin cytoskeletal regulation
}

Kentala, Henriikka

2018-03

Kentala , H , Koponen , A , Kivelä , A M , Andrews , R , Li , C , Zhou , Y \& Olkkonen , V M 2018 , ' Analysis of ORP2-knockout hepatocytes uncovers a novel function in actin cytoskeletal regulation ' , FASEB Journal , vol. 32 , no. 3 , pp. 1281-1295 . https://doi.org/10.1096/fj.201700604R

http://hdl.handle.net/10138/233965

https://doi.org/10.1096/fj.201700604R

publishedVersion

Downloaded from Helda, University of Helsinki institutional repository.

This is an electronic reprint of the original article.

This reprint may differ from the original in pagination and typographic detail.

Please cite the original version. 


\title{
Analysis of ORP2-knockout hepatocytes uncovers a novel function in actin cytoskeletal regulation
}

\author{
Henriikka Kentala, ${ }^{*}$ Annika Koponen, ${ }^{*}$ Annukka M. Kivelä, ${ }^{*}$ Robert Andrews, ${ }^{\dagger}$ ChunHei Li, ${ }^{+, \neq}$You Zhou, ${ }^{*}+,+\neq$ \\ and Vesa M. Olkkonen*,\$,1 \\ ${ }^{*}$ Minerva Foundation Institute for Medical Research, Helsinki, Finland; ${ }^{\dagger}$ Systems Immunity Research Institute and ${ }^{\ddagger}$ Division of Infection and \\ Immunity, Cardiff University School of Medicine, Cardiff University, Cardiff, United Kingdom; and ${ }^{\S}$ Department of Anatomy, Faculty of \\ Medicine, University of Helsinki, Finland
}

\begin{abstract}
ORP2 is implicated in cholesterol transport, triglyceride metabolism, and adrenocortical steroid hormone production. We addressed ORP2 function in hepatocytes by generating ORP2-knockout (KO) HuH7 cells by CRISPR-Cas9 gene editing, followed by analyses of transcriptome, F-actin morphology, migration, adhesion, and proliferation. RNA sequencing of ORP2-KO cells revealed >2-fold changes in $579 \mathrm{mRNAs}$. The Ingenuity Pathway Analysis (IPA) uncovered alterations in the following functional categories: cellular movement, cell-cell signaling and interaction, cellular development, cellular function and maintenance, cellular growth and proliferation, and cell morphology. Many pathways in these categories involved actin cytoskeleton, cell migration, adhesion, or proliferation. Analysis of the ORP2 interactome uncovered 109 putative new partners. Their IPA analysis revealed Ras homolog A (RhoA) signaling as the most significant pathway. Interactions of ORP2 with SEPT9, MLC12, and ARHGAP12 were validated by independent assays. ORP2-KO resulted in abnormal F-actin morphology characterized by impaired capacity to form lamellipodia, migration defect, and impaired adhesion and proliferation. Rescue of the migration phenotype and generation of typical cell surface morphology required an intact ORP2 phosphoinositide binding site, suggesting that ORP2 function involves phosphoinositide binding and transport. The results point at a novel function of ORP2 as a lipid-sensing regulator of the actin cytoskeleton, with impacts on hepatocellular migration, adhesion, and proliferation.-Kentala, H., Koponen, A., Kivelä, A. M., Andrews, R., Li, C., Zhou, Y., Olkkonen, V. M. Analysis of ORP2-knockout hepatocytes uncovers a novel function in actin cytoskeletal regulation. FASEB J. 32, 1281-1295 (2018). www.fasebj.org
\end{abstract}

KEY WORDS: CRISPR-Cas9 · F-actin · interactome · OSBPL2 - RNA sequencing

Oxysterol binding protein (OSBP)-related proteins (ORPs) are an evolutionarily conserved family of 12 mammalian lipid-binding proteins. OSBP/ORPs are characterized as intracellular lipid transporters or sensors with implications in various cellular processes,

ABBREVIATIONS: ARHGAP, Rho GTPase-activating protein; CRISPR, clustered regularly interspaced short palindromic repeats; DIAPH, diaphanousrelated formin; ER, endoplasmic reticulum; FBS, fetal bovine serum; gRNA, guide RNA; GBU, Genome Biology Unit; GFP, green fluorescent protein; GST, glutathione $S$-transferase; HA, hemagglutinin; IPA, Ingenuity Pathway Analysis; IQGAP, Ras GTPase-activating-like protein; KO, knockout; LD, lipid droplet; LV, lentivirus; MCS, membrane contact site; MLC, myosin light chain; MOI, multiplicity of infection; OHC, hydroxycholesterol; ORP, oxysterol binding protein-related protein; OSBP, oxysterol-binding protein; $\mathrm{PH}$, pleckstrin homology; PI4P, phosphatidylinositol-4-phosphate; PIP, phosphatidylinositol-phosphate; RhoA, Ras homolog A; ROCK, rho-associated protein kinase; sh, short hairpin; SEPT, septin; TG, triacylglycerol; VAP, VAMP-associated protein

${ }^{1}$ Correspondence: Minerva Foundation Institute for Medical Research, Biomedicum 2U, Tukholmankatu 8, FI-00290, Helsinki, Finland. E-mail: vesa.olkkonen@helsinki.fi

doi: $10.1096 /$ fj.201700604R

This article includes supplemental data. Please visit $h t t p: / / w w w$ fasebj.org to obtain this information. including nonvesicular lipid transport, membrane trafficking and cell signaling (1-3). ORP2 is ubiquitously expressed (4), and the protein is readily detectable by Western analysis in hepatoma cells such as $\mathrm{HuH7}$, in immortalized noncancerous human hepatocytes, and in human liver tissue. Similar to most of the ORPs, ORP2 is a cytosolic protein but also associates peripherally with cell membranes. ORP2 lacks a membrane targeting the phosphatidylinositol-phosphate (PIP)-sensing pleckstrin homology $(\mathrm{PH})$ domain found in the ORPs. Nevertheless, ORP2 targets the surface of the intracellular lipid droplets (LDs) and, under specific ligand conditions, the plasma membrane (5). It also associates with the endoplasmic reticulum (ER) via the ER trans-membrane proteins VAMPassociated protein A and B (VAP-A and -B). Via these distinct membrane interactions, ORP2 localizes at ER-LD membrane contact sites (MCSs) (3). The ORP2-VAP MCS tethering is reversible, however; treatment of cells with the high-affinity ligand of ORP2, 22(R)-hydroxycholesterol (OHC) (5) induces a translocation of ORP2-VAP-A complexes from the LD surface (3). 
The cellular function of ORP2 has been suggested to associate with cholesterol and triacylglycerol (TG) homeostasis (5-7). Moreover, Escajadillo et al. (8) observed that ORP2 knockdown in adrenocortical cells down-regulated key enzymes of cortisol biosynthesis and reduced the cellular concentrations of several steroid metabolites. The suppression of ORP2 was also found to increase the cellular level of cholesterol and decrease 22(R)-OHC and 7KC. Sewer and colleagues (9) reported a direct interaction between ORP2 and Ras homolog (Rho)A effector protein diaphanous-related formin (DIAPH)-1, a component involved in RhoA signaling and with an important role in adrenocortical steroid hormone production (10).

Besides the above observations linking ORP2 function to cellular lipid homeostasis and synthesis of steroid hormones, the protein was found to localize to the stereocilia of cochlear inner and outer hair cells. Heterozygous mutations in the OSBPL2 gene encoding ORP2 were reported to cause an autosomal dominant nonsyndromic hearing loss $(11,12)$.

The present study provides novel clues of the cellular function of ORP2 beyond lipid metabolism. Identification of ORP2 interaction partners and RNA sequencing of ORP2-knockout $(\mathrm{KO})$ hepatocytes suggest a connection between ORP2 and actin cytoskeletal regulation via RhoA signaling. Consistently, ORP2 knockout resulted in an inhibition of cell adhesion, migration, and proliferation.

\section{MATERIALS AND METHODS}

\section{Antibodies and other reagents}

The rabbit anti-ORP2 antibody was described in Laitinen et al. (4). Anti- $\beta$-actin and anti-cortactin were from Millipore-Sigma (Billerica, MA, USA), and anti- Ras GTPase-activating-like protein (IQGAP)-1 and anti-green fluorescent protein (GFP) were from BD Biosciences (San Jose, CA, USA). Oregon green 488 phalloidin and the fluorescent secondary antibody (Alexa Fluor-594 goat anti-mouse) were from Thermo Fisher Scientific (Waltham, MA, USA). Magnetic anti-hemagglutinin (HA) beads were purchased from Thermo Fisher Scientific and antiV5 beads from MBL (Woburn, MA, USA). Latrunculin B, Y27632, and insulin were from Millipore-Sigma.

\section{CDNA constructs}

HA epitope-tagged ORP2 was generated by inserting a double HA tag in a $B g l I I$ restriction site between the $\mathrm{N}$-terminal Venus fragment of ORP2 in VN-ORP2 (7). For overexpression of wild-type ORP2, the cDNA was inserted between the BglII and $K p n I$ sites of the pmCherry-C1 vector (Takara Bio, Mountain View, CA, USA). ORP2 mPIP (H178-179A, K423A) and mFFAT (F7-8V, D9V) mutants have been described in Weber-Boyvan et al. (7) and were similarly inserted into pmCherry. For production of recombinant glutathione $S$-transferase (GST)-ORP2 in Spodoptera frugiperda Sf9 cells GST-ORP2 was PCR amplified from ORP2pGEX1 $\lambda$ T plasmid (4) and cloned into pFastBac1 vector (obtained from BioMediTech Protein Technologies Core Facility) using XhoI and $K p n I$ restriction sites. GFP fusion expression constructs of SEPT9 and MLC12 were generated with the Gateway system (Thermo Fisher Scientific) at the University of Helsinki Genome Biology Unit (GBU). Likewise, ORP2 tagged at the $C$ terminus with V5 epitope was generated by using the Gateway System. The GFP- rho GTPase activating protein 12 (ARHGAP12) expression construct was obtained from Dr. Michael Courtney (University of Turku, Turku, Finland).

\section{Light and fluorescence microscopy}

Bright-field microscopy images were acquired with the Evos XL Cell Imaging System (AMG; Thermo Fisher Scientific). Fluorescence signals were detected with an Axio Observer Z1 microscope with an ECPlnN $\times 400.75$ DICII or a PlnApo $\times 63 / 1.40$ oil DICII objective and Colibri laser (Zeiss, Oberkochen, Germany). Images were recorded with the Zen 2 v.2.0.0 software (Zeiss). Image panels were created with Adobe Photoshop 7 software (San Jose, CA, USA).

\section{Guide RNA constructs}

The ORP2 protein was stably knocked out in HuH7 cells via double RNA-guided clustered regularly interspaced short palindromic repeats (CRISPR) with Cas9-nickase endonuclease activity. Guide RNAs (gRNAs) to target the endogenous OSBPL2 were designed with the CRISPR design tool (http://crispr.mit.edu/; Massachusetts Institute of Technology, Cambridge, MA, USA) with nickase analysis. The designed gRNA primers are listed in Table 1. The pGL3-puro-sgRNA $(13,14)$ (obtained from Dr. Shiqian Li, Department of Anatomy, University of Helsinki) vector was digested with $B b s I$ and the annealed parallel gRNA sense and antisense primers were ligated into the vector with T4 ligase (New England Biolabs, Ipswich, MA, USA) according to the manufacturer's instructions. Plasmids were transformed into Escherichia coli DH5 $\alpha$ (New England Biolabs) and verified by sequencing.

\section{Generation of stable ORP2-KO HuH7 cell lines}

The HuH7 human hepatoma cell line (15) was cultured as described in Kentala et al. (3). HuH7 cells were seeded into 12-well plates and transfected using Lipofectamine 2000 (Thermo Fisher

TABLE 1. The OSBPL2-specific gRNA primers

\begin{tabular}{lll}
\hline \hline & \multicolumn{2}{c}{ Sequence } \\
\cline { 2 - 3 } OSBPL2 target & \multicolumn{1}{c}{ Sense } & Antisense \\
\hline Exon 4 & & \\
Guide 4-A & CACCGAAGTCGCTTCTGCTGAACAT & AAACATGTTCAGCAGAAGCGACTTC \\
Guide 4-B & CACCGACCATCCTGAAGAAGTGTGT & AAACACACACTTCTTCAGGATGGTC \\
Exon 5 & & \\
Guide 5-A & CACCGAGAGGCTCGTTGAAGGCGAT & AAACATCGCCTTCAACGAGCCTCTC \\
Guide 5-B & CACCGCAGCGGATCACGGAGTACA & AAACTGTACTCCGTGATCCGCTGC \\
\hline
\end{tabular}


Scientific). Transfection mixtures contained $0.4 \mu \mathrm{g}$ gRNA 5-A and $0.4 \mu \mathrm{g}$ gRNA guide 5 -B or $0.2 \mu \mathrm{g}$ gRNA guide $4-\mathrm{A}, 0.2 \mu \mathrm{g}$ gRNA guide 4-B, $0.2 \mu \mathrm{g}$ gRNA guide $5-\mathrm{A}$, and $0.2 \mu \mathrm{g}$ gRNA guide 5-B, combined with $1.2 \mu$ g Cas9n $(13,14)$ (pcDNA4-Cas9n2A-GFP, obtained from Dr. Shiqian Li) and $4 \mu$ l Lipofectamine 2000. Cas9 control HuH7 cells were prepared without adding the OSBPL2 specific gRNA constructs into the transfection mixture. At $24 \mathrm{~h}$ after transfection, the cells were subjected to fluorescenceactivated cell sorting (FACSAriaII; BD Biosciences) at the Biomedicum Flow Cytometry Core Facility (Helsinki, Finland). Single-cell clones were cultured for $3 \mathrm{wk}$ to generate stable ORP2$\mathrm{KO}$ cell lines. The ORP2-KO cell lines are referred to herein as ORP2-KO1 (for guide 5) and ORP2-KO2 (for guide 4+guide $5)$. The effectiveness of ORP2-KO was analyzed by Western blot analysis with anti-ORP2 antibody. The defects generated were identified in ORP2 cDNA by amplifying the exon 4-5 region, cloning the PCR products, and sequencing inserts from each cell line.

\section{Generation of recombinant lentiviruses}

ORP2 cDNAs were subcloned into the Gateway entry vector pENTR2B (Thermo Fisher Scientific). The constructs were recombined into pLenti7.3/V5-DEST at the GBU (Helsinki University), and recombinant lentiviruses (LVs) were packaged and concentrated to $\mathrm{p} 24$ concentrations of $3-8 \times 10^{7} \mathrm{pg} / \mathrm{ml}$ by the Biomedicum Functional Genomics Unit, HiLife Institute (Helsinki, Finland). A short hairpin (sh)RNA LV for knockdown of ORP2 was generated by using the shRNA clone TRCN000154381 in pLKO.1 (Millipore-Sigma), which was used for virus (LV-shORP2) packaging, as previously described. The shScramble construct SHCO02 (Millipore-Sigma) was used for generating a nontargeting control (LV-shScramble).

\section{Culture and LV transduction/electroporation of primary endothelial cells}

HUVECs purchased from Lonza (Basel, Switzerland) were grown on fibronectin gelatin-coated flasks in endothelial cell growth medium $[0.1 \%$ human epidermal growth factor, $0.1 \%$ hydrocortisone, $0.1 \%$ gentamicin-amphotericin $\mathrm{B}, 0.4 \%$ bovine brain extract, and $2 \%$ fetal bovine serum (FBS); Lonza]. For ORP2 silencing, HUVECs were transduced for $72 \mathrm{~h}$ with LV-shORP2 or LV-shScramble (control) using a multiplicity of infection (MOI) of 10. For ORP2 overexpression, HUVECs were transfected with ORP2 or control GFP plasmids with an HUVEC Nucleofector Kit (Lonza), according to the manufacturer's protocol.

\section{RNA sequencing and pathway analysis}

For RNA sequencing, samples were prepared from 4 parallel cultures each of ORP2-KO1, ORP2-KO2 and Cas9 control HuH7 cells using the TruSeq Stranded Total RNA Library Prep Kit with Ribo-Zero (Illumina, San Diego, CA, USA). The Burrows-Wheeler aligner (16) was used to align output reads to the human reference genome (GRCh38). The FeatureCounts program (17) was used to count mapped fragments against genomic features defined by the Ensembl annotation file (homo_sapiens.GRCh38.76.gtf). The genes with counts $\leq 1$ in all samples were removed, and Deseq2 was used to analyze the differential gene expression (18). The BenjaminiHochberg test was used to control the false discovery rate. Genes that differed significantly between ORP2-KO1 and Cas 9 control cells (fold change, $\log _{2}>1$ ) were selected for analysis by the Ingenuity Pathways Analysis tool (IPA;
Qiagen, Hilden, Germany). Enrichment of the genes in the pathways was assessed in comparison with a reference set in the whole Ingenuity pathway knowledge base. A volcano plot was built by using the $\log _{10}$-adjusted $P$ value against a $\log _{2}$ expression change of each gene in response to knock out of ORP2 in HuH7 cells. Googlevis was used to generate a Google interactive chart (19).

\section{Cell migration assays}

Wound-healing assays with Huh7, Cas9 control, and ORP2$\mathrm{KO}$ or ORP2-KO cells infected for $48 \mathrm{~h}$ with LVs overexpressing GFP (ctrl), WT ORP2, ORP2 (mFFAT) or ORP2 (mPIP) at a MOI 10 were performed (20). In addition, cell migration was measured with the $x$ Celligence Real-Time Cell Analysis system with a DP instrument (Acea Biosciences, San Diego, CA, USA). ORP2-KO and Cas9 control cells were seeded at $3 \times 10^{4}$ cells per chamber in the top chambers in medium depleted of FBS (CIM-plate 16; Acea Biosciences). The bottom electronically integrated Boyden chambers contained basal growth medium with $10 \%$ FBS. Cell movement from the top to the bottom chamber was monitored for $24 \mathrm{~h}$ in real time by electrical impedance at $37^{\circ} \mathrm{C}$, in a humidified $5 \% \mathrm{CO}_{2}$ atmosphere with Radio Technical Commission for Aeronautics (RTCA) Software 1.2 (Acea Biosciences).

\section{Cell adhesion and proliferation assay}

Cell adhesion to substratum and proliferation were measured with xCelligence Real-Time Cell Analysis system with the DP instrument (Acea Biosciences). HuH7, ORP2-KO, and Cas 9 control cells were seeded at $8 \times 10^{3}$ cells per well on electronic microtiter plates with noninvasive gold microelectrode biosensors (E-plate 16; Acea Biosciences). The electrical impedance was monitored for $85 \mathrm{~h}$ in real time at $37^{\circ} \mathrm{C}$ in a humidified $5 \% \mathrm{CO}_{2}$ atmosphere with RTCA Software 1 . Cell proliferation and adhesion were analyzed with the same software.

\section{Anti-HA coimmunoprecipitation and proteomics}

$\mathrm{HuH7}$ cells grown in $10 \mathrm{~cm}$ dishes were transfected with HAORP2 or ORP2 expression plasmids using Lipofectamine 2000 (Thermo Fisher Scientific). After $24 \mathrm{~h}$, the cells were lysed in lysis buffer [10 mM HEPES (pH 7.6), $150 \mathrm{mM} \mathrm{NaCl}, 0.5 \mathrm{mM} \mathrm{MgCl}$, $10 \%$ glycerol, $0.5 \%$ Triton $\mathrm{X}-100,0.5 \%$ saponin, protease inhibitor cocktail], mixed thoroughly by vortexing and incubated on ice for $10 \mathrm{~min}$. Unbroken cells and insoluble material were removed by centrifugation at 20,000 $g$ for $10 \mathrm{~min}$. The obtained lysates were mixed with $30 \mu l$ of protein $G$ magnetic beads (Thermo Fisher Scientific) and incubated for $30 \mathrm{~min}$ on rotation at $4^{\circ} \mathrm{C}$ to remove material unspecifically bound to the beads. After removing the beads, $30 \mu$ l of anti-HA magnetic beads (Thermo Fisher Scientific) were added and incubated for $1.5 \mathrm{~h}$ on rotation at $4^{\circ} \mathrm{C}$. The beads were washed 3 times with lysis buffer and 2 times with deionized $\mathrm{H}_{2} \mathrm{O}$. Bound proteins were eluted with $100 \mu \mathrm{l}$ of $0.1 \mathrm{M}$ glycine ( $\mathrm{pH} 2.0$ ) for $30 \mathrm{~min}$ at room temperature. The alkaline elution was neutralized with $8 \mu \mathrm{l}$ of $1 \mathrm{M}$ Tris base ( $\mathrm{pH} 9.0$ ) before analysis of the eluted protein with mass spectrometry of tryptic peptides at the Meilahti Clinical Proteomic Core Facility (University of Helsinki). The background proteins identified in the ORP2 sample lacking an HA epitope tag were subtracted from the proteins identified in the anti-HA-precipitated HA-ORP2 sample. The list of putative interaction partners of ORP2 was subjected to IPA analysis as previously described. 


\section{Pulldown and coimmunoprecipitation assays}

HuH7 cells were transfected with GFP-SEPT9 or GFPARHGAP12 plasmid using Lipofectamine 2000 (Thermo Fisher Scientific) or left untransfected for the pulldown of endogenous proteins. After $24 \mathrm{~h}$, the cells were washed and lysed in lysis buffer [10 mM HEPES (pH 7.6), $150 \mathrm{mM} \mathrm{NaCl}, 0.5 \mathrm{mM} \mathrm{MgCl}_{2}, 10 \%$ glycerol, $0.5 \%$ Triton X-100, $0.5 \%$ Na-deoxycholate, protease inhibitor cocktail (Roche Diagnostics, Basel, Switzerland)], mixed thoroughly and incubated on ice for $10 \mathrm{~min}$. Unbroken cells and insoluble material were removed by centrifugation at 20,000 $g$ for $10 \mathrm{~min}$. The obtained lysates were incubated with $300 \mu \mathrm{M}$ GST-ORP2 or GST (produced in Sf9 cells by the BioMediTech Protein Technologies core facility) and $20 \mu$ l glutathioneSepharose 4B (GE Healthcare, Waukesha, WI, USA) for $2 \mathrm{~h}$ at $4^{\circ} \mathrm{C}$. The beads were washed 4 times with lysis buffer, resuspended in $30 \mu \mathrm{l}$ Laemmli sample buffer and boiled for $5 \mathrm{~min}$. The bound proteins were detected with anti-GFP or -IQGAP1 antibodies.

The ORP2-V5 coimmunoprecipitation was performed similarly: HuH7 cells were transfected with ORP2-V5 and GFPmyosin light chain (MLC)-12 or GFP-MLC12 alone as a negative control. The cell lysates were first incubated with $15 \mu \mathrm{l}$ anti-HA Magnetic Beads (Thermo Fisher Scientific) to reduce the unspecific binding for $30 \mathrm{~min}$ at $4^{\circ} \mathrm{C}$, followed by an incubation with $40 \mu \mathrm{l}$ anti-V5 magnetic beads (MBL) overnight at $4^{\circ} \mathrm{C}$. The beads were washed 4 times with lysis buffer, resuspended in $30 \mu l$ Laemmli sample buffer, and boiled for $5 \mathrm{~min}$. The bound proteins were detected with anti-GFP antibody.

\section{Analyses of OSBPL2 expression in cancer tissue transcriptomes}

mRNA sequencing data were downloaded from 2 cohorts including 89 samples from patients with kidney chromophobe carcinoma. We excluded mRNAs with no counts in more than $50 \%$ of the samples in each cohort. Deseq 2 was used to analyze the differential gene expression. cBioportal ( $h t t p: / / w w w . c b i o p o r t a l$. org/) was used to visualize the gene amplification in tumors.

\section{Statistical analyses}

In the IPA analysis, Fisher's exact test was used to determine the significance of each pathway and the Benjamini-Hochberg method was used to control for false discovery rate. Statistical analysis of cell biologic assays was performed by using an independent, 2-tailed Student's $t$ test.

\section{Other methods}

Immunofluorescence staining was performed as described in Kentala et al. (3) and Western blot analysis as in Weber-Boyvat et al. (7).

\section{RESULTS}

\section{Depletion of ORP2 in HuH7 cells subjected to CRISPR-Cas9 gene editing}

The endogenous OSBPL2 gene of $\mathrm{HuH7}$ cells was abrogated by using the CRISPR-Cas9 genome editing technique with ORP2-specific gRNAs. gRNAs were targeted to exons 4 and 5 of OSBPL2. The CRISPR-Cas9 mutations resulted in 14-131 nucleotide deletions in the OSBPL2
cDNA (Fig. 1A) and premature termination codons after the amino acid residues 102-153 of ORP2. The ORP2 protein was completely absent in both $\mathrm{KO}$ cell lines, as evidenced by Western blot analysis with anti-ORP2 antibody (Fig. 1B). Upon culture, the ORP2-KO cells appeared markedly different from the Cas9-transfected controls: they failed to grow as even monolayers but displayed a strong tendency to form islet-like cell clusters (Fig. 1C).

\section{Altered mRNAs of multiple signaling pathways suggest novel roles for ORP2 in cellular functions beyond lipid metabolism}

The next generation RNA sequencing of ORP2-KO hepatocytes indicated that loss of ORP2 affects the quantity of $>2000$ transcripts (Supplemental Fig. S1). The genes sensitive to ORP2 depletion filtered by a minimum fold change of $\times 2$ (a total of 579 genes; blue in the Supplemental Plot) were subjected to IPA, which predicted several cellular functions and cell signaling pathways to be dysregulated in the ORP2-KO cells (Fig. 2A). The IPA pathways constituting the cellular function categories cellular movement, cell-cell signaling and interaction, cellular growth and proliferation, cell death and survival and cellular assembly and organization-were affected in the ORP2-KO cells as listed in Table 2. Of note, the cellular movement category contained the cellular migration, invasion, and homing pathways, the cellular assembly and organization category, several actin cytoskeletonassociated pathways, the cell-cell signaling and interaction category, and several cell junction and adhesion pathways. The most strongly affected (according to fold change) individual genes up- or down-regulated in the ORP2-KO cells are listed in Table 3 . Of note, the most upregulated mRNAs included the RhoA effector GPR55 (21) and the adhesion molecule HEPACAM2 (22), whereas one of the most down-regulated individual mRNAs was $V C A N$ encoding versican, a proteoglycan that controls cell adhesion, migration, and proliferation (23).

OSBP/ORPs constitute a large conserved family of proteins. In principle, their functions could be overlapping and hence could be compensated for by each other $(24,25)$. We therefore specifically analyzed in ORP2-KO and control cells the mRNA levels of all ORP family members and also the ORP interaction partners VAP-A and -B. However, the RNA sequencing revealed no notable effect of ORP2 knockout on the mRNA levels of other OSBP/ORPs or the VAPs (Supplemental Fig. S2). The mRNAs for all ORPs except ORP5, as well as VAP-A and -B, were present in the ORP2-KO and Cas9 control HuH7 cells. The observation indicated that the phenotypic alterations in the ORP2-KO cells are not significantly modified by compensatory changes in the expression of other ORPs or VAPs.

\section{ORP2 knockout and reexpression modify the actin cytoskeleton}

The molecular and cellular functions affected in the ORP2KO cells, as suggested by the IPA analysis included several 


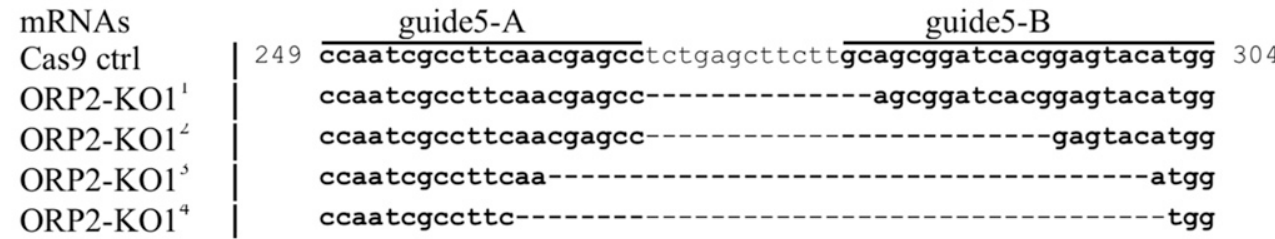

mRNAs

Cas9 ctrl

ORP2-KO2

ORP2-KO2 ${ }^{2}$

Cas9 ctrl

ORP2-KO2

ORP2-KO2 ${ }^{2}$

guide4-A

guide4-B

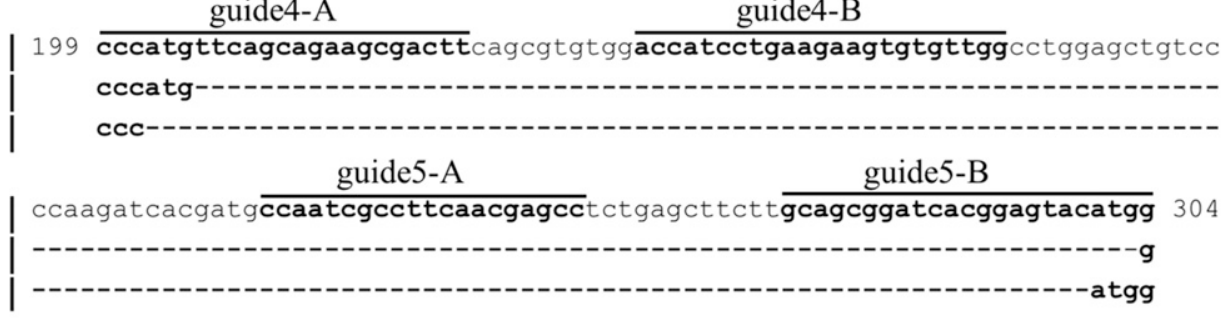

B

C
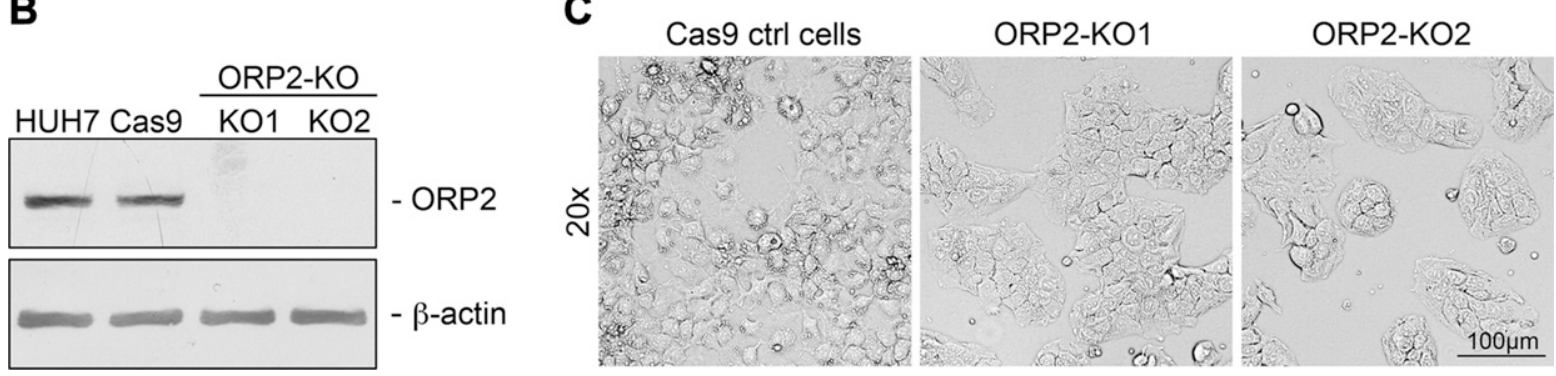

Figure 1. ORP2 KO in HuH7 hepatoma cells. A) The CRISPR-Cas9-derived mutations in the ORP2-KO1 and -KO2 cell lines identified by sequencing. B) Detection of endogenous ORP2 by Western blot from native HuH7, Cas9 control, ORP2-KO1 and ORP2-KO2 cell lysates with anti-ORP2 antibody. $\beta$-Actin is shown as the loading control. $C$ ) Light microscopy images of Cas9 control and ORP2-KO HuH7 cultures.

pathways involving the actin cytoskeleton (Table 2). We therefore visualized F-actin in ORP2-KO and Cas9 control $\mathrm{HuH7}$ cells with fluorescent phalloidin in the presence or absence of insulin stimulation and stained the leading edge of the cells with anti-cortactin (Fig. 2B). The ORP2$\mathrm{KO}$ cells displayed remarkable defects in the organization of F-actin and formation of leading edge. In the ORP2-KO cells, cortactin ${ }^{+}$polarized lamellipodia were absent (Fig. $2 C)$, and cortactin was instead distributed to the cell surface blebs (Fig. 2D).

To further analyze the impact of ORP2 on the actin cytoskeleton, ORP2 was overexpressed in the $\mathrm{KO}$ and Cas 9 cells by transfection of mCherry-ORP2 or plain mCherry as a negative control. The overexpression of ORP2 abolished the stress fibers and induced prominent F-actin ${ }^{+}$plasma membrane ruffles and cell surface protrusions or filopodia-like structures in both Cas9 control and ORP2-KO cells (Fig. $3 A, B$ and Supplemental Fig. S3 $A, B$ ). These observations are fully consistent with the observed mRNA alterations in multiple pathways involving the actin cytoskeleton, cell adhesion, and migration. Of note, overexpression of an ORP2 mutant with the conserved PIP-binding cleft inactivated [ORP2(mPIP) (7)] failed to induce morphologic changes in actin-enriched plasma membrane structures in the Cas9 controls or the ORP2-KO cells (Fig. 3C and Supplemental Fig. S3C), whereas a mutant incapable of binding the VAPs [ORP2(mFFAT) (7)] behaved similarly in this morphologic assay to the wildtype protein (Fig. 3D and Supplemental Fig. S3D).

To investigate whether the morphologic phenotypes caused by ORP2 depletion or overexpression are also detectable in other, noncancerous cells, we knocked down ORP2 in primary HUVECs by using recombinant LVs or overexpressed it by plasmid electroporation. The cells depleted of ORP2 displayed, in the presence or absence of insulin stimulation, a disturbance of cell F-actin morphology similar to that of the ORP2-KO cells: loss of stress fibers, a rounded morphology with an apparent defect in spreading on the substratum, and a robust induction of cell surface blebs (Supplemental Fig. S4A, B). In contrast, overexpression of ORP2 in HUVECs induced abundant formation of cortactin ${ }^{+}$lamellipodia (Supplemental Fig. $S 4 C, D)$. These observations suggest that the actin phenotype observed in ORP2-KO cells is not limited to hepatic or cancerous cells.

\section{The ORP2 interactome suggests an involvement of the protein in RhoA signaling}

To further elucidate the molecular mechanisms of ORP2 action, a proteomic analysis of the ORP2 interactome was performed. HA-tagged ORP2, or a similar construct lacking the HA epitope as a negative control, was expressed in HuH7 cells, followed a pulldown by of complexes with 
A

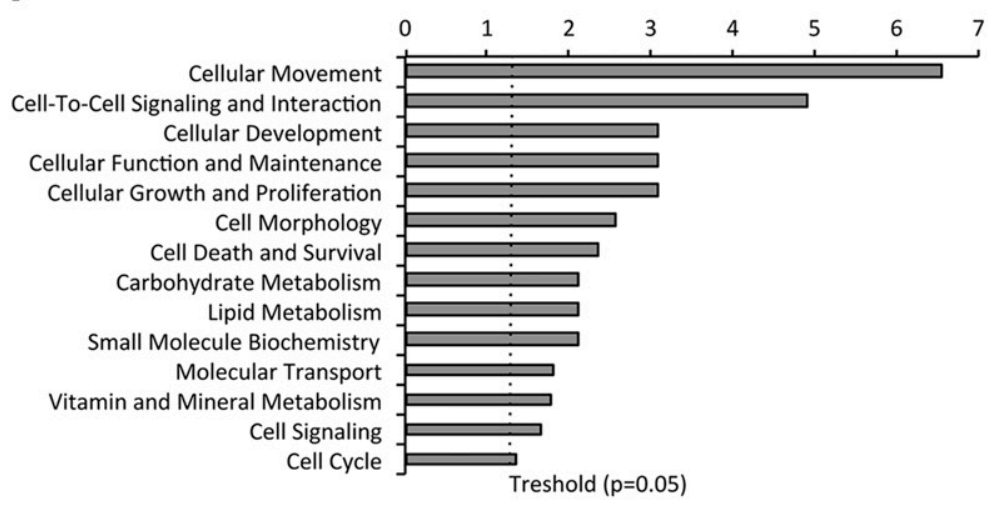

B

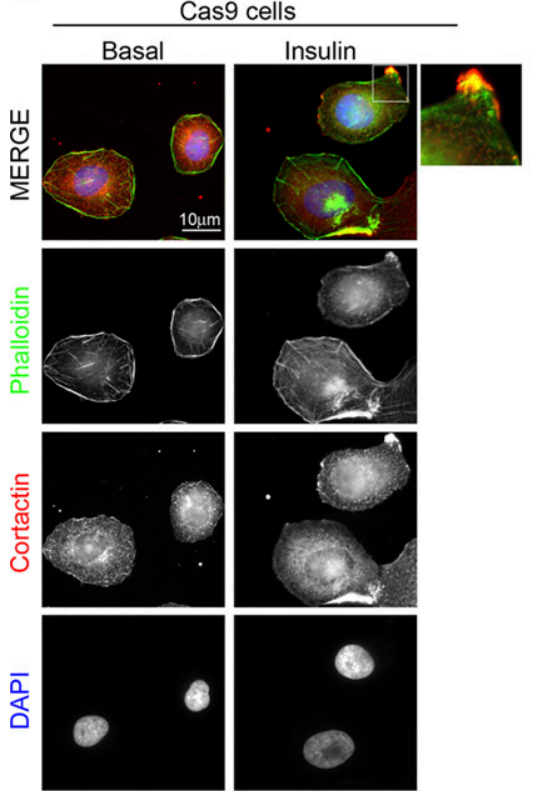

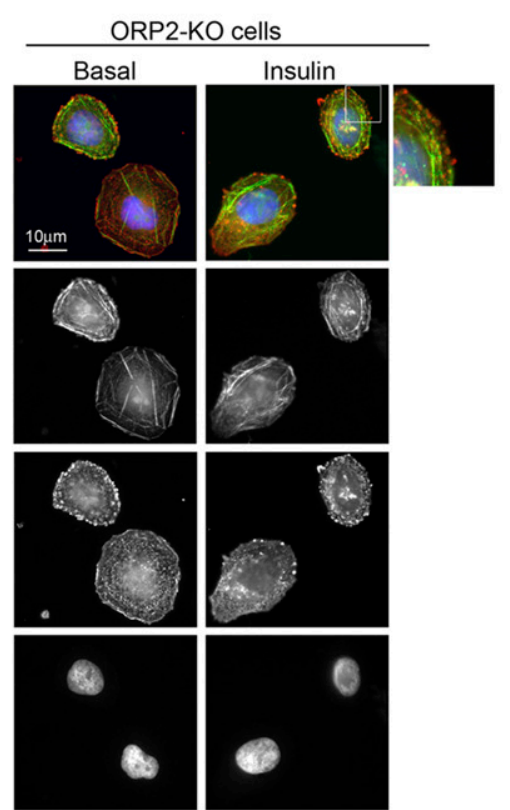

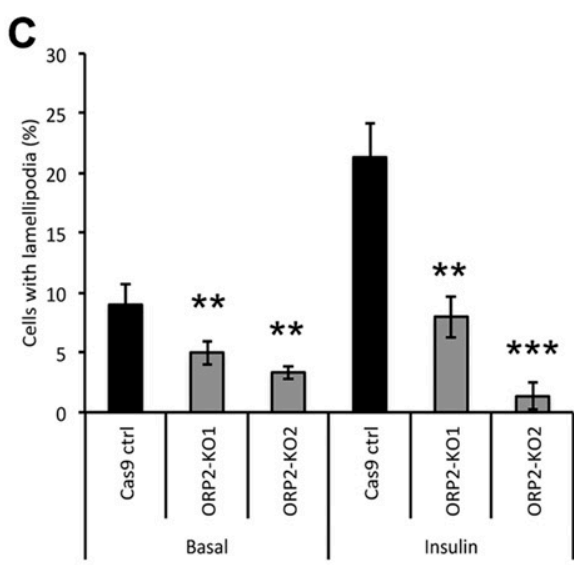

D

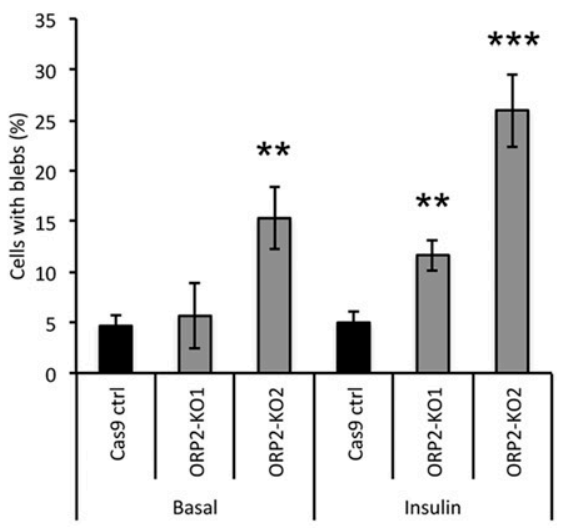

Figure 2. Molecular and cellular functions affected in the ORP2-KO cells. A) The molecular and cellular functions (RNA sequencing analysis) significantly affected in the ORP2-KO cells were identified. $P<0.05$ after multiple test adjustment was considered statistically significant, and mRNAs changed at least 2-fold (579 species) were included. B) Staining of cortactin with an antibody and F-actin with fluorescent green phalloidin in Cas9 control and ORP2-KO cells grown in basal growth medium or stimulated for $10 \mathrm{~min}$ with $200 \mathrm{nM}$ insulin. The nuclei are visualized with DAPI. C) Quantification of cells containing lamellipodia from 2 independent experiments (a total of 300 cells analyzed). D) Quantification of cells containing blebs from 2 independent experiments (a total of 300 cells analyzed). $* * P<0.01$, *** $P<0.001$.

anti-HA magnetic beads. Mass spectrometric analysis of tryptic peptides identified 111 proteins that were found specifically in the HA-ORP2 complexes, but were absent in the negative control (Supplemental Table S1). Of note, these proteins included the known binding partners of ORP2 and VAP-A and -B. Several of the putative interaction partners represent intramitochondrial components, indicating that some unspecific binding may have occurred during isolation of the complexes. Similar to the RNA sequencing data, the potential interacting components were subjected to IPA analysis. Strikingly, the most significant pathway identified in the ORP2 interactome was RhoA signaling (for overlapping genes, $P=0.006$ ). The 6 putative ORP2 interaction partners in the RhoA signaling pathway were septin 9 (SEPT), ezrin (EZR), ARHGAP, phosphatidylinositol 4-kinase $\alpha$ (PI4KA) and MLC $12 \mathrm{~A}$ and 12B (Fig. $4 A$, blue). Of these tentative partners, binding of SEPT9, ARHGAP12, and MLC12 to ORP2 was validated by an independent pulldown assay. Lysates from HuH7 cells overexpressing GFP-SEPT9 and GFP-ARHGAP12 were subjected to pulldown with recombinant GST-ORP2 and glutathione Sepharose, followed by Western analysis with anti-GFP. The negative GST control showed no immunoreactivity, the GSTORP2 pull-down contained abundant GFP-SEPT9 and GFP-ARHGAP12 (Fig. 4B), supporting a specific interaction of both proteins with ORP2. MLC12 showed a strong binding to GST alone (data not shown); hence, the interaction between ORP2 and GFP-MLC12 was confirmed by coimmunoprecipitation using ORP2-V5 and anti-V5 magnetic beads (Fig. 4C).

Consistent with the interactome analysis, the RNA sequencing analysis identified 12 significantly dysregulated mRNAs of components of the RhoA signaling pathway in 
TABLE 2. Cellular functions related to the mRNAs affected by ORP2-KO

\begin{tabular}{|c|c|c|}
\hline Cellular function & Adj. H-B $P$ & Gene $(n)$ \\
\hline \multicolumn{3}{|l|}{ Cellular movement } \\
\hline Cell movement & $1.30 \times 10^{-13}$ & 225 \\
\hline Migration of cells & $4.54 \times 10^{-11}$ & 194 \\
\hline Invasion of cells & $9.08 \times 10^{-11}$ & 132 \\
\hline Homing of cells & $3.72 \times 10^{-7}$ & 62 \\
\hline Chemotaxis & $8.54 \times 10^{-7}$ & 60 \\
\hline \multicolumn{3}{|l|}{ Cell-cell signaling and interaction } \\
\hline Adhesion & $6.16 \times 10^{-6}$ & 50 \\
\hline Communication of cells & $9.84 \times 10^{-5}$ & 113 \\
\hline Intercellular communication & $3.76 \times 10^{-4}$ & 26 \\
\hline Assembly of intercellular junctions & $5.05 \times 10^{-4}$ & 13 \\
\hline $\begin{array}{l}\text { Disruption of intercellular } \\
\text { junctions }\end{array}$ & $6.75 \times 10^{-4}$ & 6 \\
\hline Formation cell-cell contact & $1.39 \times 10^{-3}$ & 14 \\
\hline Disruption of tight junctions & $1.70 \times 10^{-3}$ & 5 \\
\hline Signal transduction & $3.26 \times 10^{-3}$ & 92 \\
\hline Association of plasma membrane & $3.59 \times 10^{-3}$ & 3 \\
\hline Development of gap junctions & $3.64 \times 10^{-3}$ & 9 \\
\hline \multicolumn{3}{|l|}{ Cellular growth and proliferation } \\
\hline Proliferation of cells & $8.62 \times 10^{-7}$ & 223 \\
\hline Maturation & $2.14 \times 10^{-4}$ & 5 \\
\hline Differentiation & $6.64 \times 10^{-4}$ & 22 \\
\hline Cytostasis & $1.11 \times 10^{-3}$ & 5 \\
\hline Colony formation & $1.31 \times 10^{-3}$ & 57 \\
\hline \multicolumn{3}{|l|}{ Cell death and survival } \\
\hline Cell death & $3.09 \times 10^{-5}$ & 283 \\
\hline Apoptosis & $1.37 \times 10^{-4}$ & 220 \\
\hline Cell viability & $4.11 \times 10^{-4}$ & 10 \\
\hline Necrosis & $4.18 \times 10^{-4}$ & 234 \\
\hline Cell survival & $3.59 \times 10^{-3}$ & 3 \\
\hline \multicolumn{3}{|l|}{ Cellular assembly and organization } \\
\hline Assembly of cells & $1.54 \times 10^{-6}$ & 44 \\
\hline Tubulation of cells & $1.12 \times 10^{-3}$ & 20 \\
\hline Formation of membrane ruffles & $1.38 \times 10^{-3}$ & 6 \\
\hline Formation of cellular protrusions & $1.56 \times 10^{-3}$ & 49 \\
\hline Formation of hemidesmosomes & $3.59 \times 10^{-3}$ & 3 \\
\hline
\end{tabular}

the ORP2-KO cells. The up-regulated RhoA signaling components were Rhotekin 1 and 2, phosphatidylinositol4-phosphate 5-kinase (PI4P5K), DIAPH1, and actinrelated protein $2 / 3$ complex subunits $1 \mathrm{~A}$ and 5 (Fig. $4 A$, green), and the down-regulated ones were lysophosphatidic acid receptor (LPAR), profilin 1 and 2, Rho-associated protein kinase (ROCK)-2, G-actin 1, and cofilin-2 (Fig. 4A, red). In addition, $16 \mathrm{mRNAs}$ related to Rac1 GTP-binding protein signaling - a central pathway in the activation of the lamellipodia formation $(26,27)$-were significantly dysregulated $(P=0.03$; Supplemental Fig. S5A). The interactome analysis also suggested a physical complex between ORP2 and IQGAP1-2 (Supplemental Fig. S3A, blue), factors important in organization of the actin cytoskeleton by Rac1 and Cdc42 signaling. By employing GST-ORP2 pulldown, an interaction between ORP2 and endogenous IQGAP1 was validated (Supplemental Fig. S5B).

\section{ORP2 KO inhibits cell migration}

IPA analysis of the transcriptome of ORP2-KO cells indicated an alteration of the cell movement function in the
ORP2-KO cells (Table 2). Therefore, we studied the effect of ORP2 knockout on migration of HuH7 hepatoma cells in a wound-healing assay. Confluent monolayers of ORP2-KO, Cas9 control, and HuH7 cells were wounded by a small pipet tip, and the wound closure $(300-400 \mu \mathrm{m})$ was monitored for $22 \mathrm{~h}$ (Fig. $\mathbf{5 A}, \boldsymbol{B}$ ), a period was sufficient for Cas9 control cells to partly cover the wounded area; the mean cell migration rate was determined as $16.6-16.8 \mu \mathrm{m} / \mathrm{h}$. Migration of the ORP2-KO cells was significantly (by 30-49\%) decelerated compared with the control, the migration rate of these cells being 9.5-11.6 $\mu \mathrm{m} / \mathrm{h}$ (Fig. 5B). The ability of wild-type ORP2, ORP2(mFFAT), and ORP2(mPIP) to rescue this migration defect was tested. The wild-type and ORP2(mFFAT) overexpression enhanced wound closure in the ORP2-KO cells by $74-130 \%$ and $77-125 \%$, respectively (Fig. 5C). However, the ORP2 PIP-binding deficient mutant (mPIP) had no effect on the wound healing, compared with the GFP-expressing control LV.

The effect of ORP2-KO on cell migration was further analyzed with the xCELLigence Real-Time Cell Analysis system, by employing a transfilter migration application. Consistently, the analysis revealed a marked difference in migration between the ORP2-KO and Cas9 control cells, the KOs. showing a $65-77 \%$ reduction in the slopes of their migration curves (Fig. 5D, E). Treatment of HuH7 or Cas9 control cells with the ROCK antagonist Y27632, an established inhibitor of cell motility, resulted in this assay in a drastic reduction in migration (Supplemental Fig. S6A, B).

\section{ORP2 knockout inhibits cell adhesion and proliferation}

To investigate the putative role of ORP2 in cell adhesion and proliferation, the native $\mathrm{HuH} 7$ cells, the Cas9 controls, and the ORP2-KO cells were monitored with the xCELLigence Real-Time Cell Analysis system. Cell adhesion to the substratum was measured during the first $5 \mathrm{~h}$ after plating, followed by proliferation analysis for up to $85 \mathrm{~h}$. Adhesion of the ORP2-KO cells to the substratum was decelerated by $44-49 \%$ as compared to the maternal HuH7 cell line and the Cas9 controls (Fig. 6A, B). Proliferation of the control cells reached saturation in $50 \mathrm{~h}$, whereas the proliferation of ORP2-KO1 and ORP2-KO2 continued until $75 \mathrm{~h}$ (Fig. $6 C)$. Analysis of the proliferation curves between 5 and $50 \mathrm{~h}$ revealed a $38-64 \%$ reduction in their slopes in ORP2-KO cells, as compared to the controls, suggesting a significant proliferation defect in the cells lacking ORP2 (Fig. 6D). Treatment of HuH7 and Cas9 control cells with the actin monomer sequestering drug latrunculin B included as a control completely abolished adhesion of the cells to the microelectrode surface of the measuring chambers (Supplemental Fig. $\mathrm{S} 6 \mathrm{C})$.

The observed effects of ORP2 knockout on hepatocellular adhesion, migration, and proliferation prompted us to analyze the expression of the gene in malignant tumors in patients by using a TCGA database. Its expression was 


\begin{tabular}{|c|c|c|c|c|c|}
\hline \multicolumn{2}{|l|}{ Protein coding } & $\begin{array}{l}\text { Log expression } \\
\text { value }\end{array}$ & Adj. H-B $P$ & Cellular function & Reference \\
\hline \multicolumn{6}{|c|}{ Up-regulated genes } \\
\hline TXNIP & Thioredoxin-interacting protein & 3.70 & $5.9 \times 10^{-230}$ & Thioredoxin activity, metabolism & 69,70 \\
\hline GPR55 & GPCR 55 & 3.30 & $2.9 \times 10^{-67}$ & RhoA effector & 21 \\
\hline NELL2 & Neural EGFL like 2 & 2.65 & $2.9 \times 10^{-35}$ & Neural cell growth & 71 \\
\hline HEPACAM2 & $\begin{array}{l}\text { Hepatocyte cell adhesion molecule } \\
\text { family member } 2\end{array}$ & 2.63 & $9.4 \times 10^{-95}$ & Adhesion & 22 \\
\hline VEPH1 & $\begin{array}{l}\text { Ventricular zone expressed } \mathrm{PH} \\
\text { domain containing } 1\end{array}$ & 2.50 & $8.0 \times 10^{-35}$ & Akt regulation & 72 \\
\hline$H E P H$ & Hephaestin & 2.43 & $1.6 \times 10^{-27}$ & Ferroxidase & 73 \\
\hline$L G A L S 3 B P$ & Galectin-3-binding protein & 2.42 & $1.4 \times 10^{-218}$ & Cell-cell and cell-matrix association & 74 \\
\hline CA4 & Carbonic anhydrase 4 & 2.29 & $1.0 \times 10^{-141}$ & Catalysis of $\mathrm{CO}_{2}$ reversible hydration & 75 \\
\hline$C 4 B P B$ & $\begin{array}{l}\text { Complement component } 4 \text { binding } \\
\text { protein } \beta\end{array}$ & 2.27 & $8.9 \times 10^{-105}$ & Complement activation & 76 \\
\hline$A N X A 3$ & Annexin A3 & 2.04 & $1.8 \times 10^{-87}$ & Phospholipid binding & 77 \\
\hline \multicolumn{6}{|c|}{ Down-regulated genes } \\
\hline EDIL3 & $\begin{array}{l}\text { EGF like repeats and discoidin } \\
\text { domains } 3\end{array}$ & -2.80 & $4.2 \times 10^{-29}$ & Integrin binding & 78 \\
\hline EMC10 & $\begin{array}{l}\text { ER membrane protein complex } \\
\text { subunit } 10\end{array}$ & -2.74 & $3.8 \times 10^{-27}$ & ER-associated degradation & 79 \\
\hline NPTX2 & Neuronal pentraxin 2 & 2.71 & $2.5 \times 10^{-29}$ & Excitatory synapse formation & 80 \\
\hline МYH4 & Myosin, heavy chain 4 & -2.53 & $2.8 \times 10^{-196}$ & $\begin{array}{l}\text { Actin network disassembly, cell } \\
\text { motility }\end{array}$ & 81 \\
\hline$P L G$ & Plasminogen/plasmin & -2.40 & $4.8 \times 10^{-70}$ & Serine protease & 82 \\
\hline$V C A N$ & Versican & -2.22 & $3.7 \times 10^{-33}$ & Antiadhesion molecule & 23 \\
\hline$A R G 1$ & Arginase 1 & -2.07 & $2.6 \times 10^{-50}$ & Arginine hydrolysis & 83 \\
\hline SLC16A3 & Monocarboxylate transporter 4 & -2.06 & $1.5 \times 10^{-170}$ & PM monocarboxylate transporter & 84 \\
\hline$M B L 2$ & Mannose-binding lectin 2 & -1.98 & $3.5 \times 10^{-39}$ & Complement activation & 85 \\
\hline$E P B 41 L 3$ & $\begin{array}{l}\text { Erythrocyte membrane protein band } \\
4.1 \text { like } 3\end{array}$ & -1.96 & $9.5 \times 10^{-14}$ & Tumor suppressor & 86 \\
\hline
\end{tabular}

significantly (mean fold-change, 1.66) increased in 65 solid tumors, compared with 24 normal controls in patients with chromophobe kidney cancer $(P=7.09 \mathrm{E}-15$, adjusted $P$ $=5.81 \mathrm{E}-14)$. This observation indicates that elevated ORP2 expression associated with certain types of cancer could contribute to the malignant phenotype.

\section{DISCUSSION}

In the present study, we used CRISPR-Cas9-mediated gene editing to generate a complete $\mathrm{KO}$ of OSBPL2/ORP2 in human hepatoma cells, and performed a series of analyses to reach a comprehensive view of ORP2 function in cell physiology. The viability of the ORP2-KO cells suggested that ORP2 is not essential for cell survival, as is the case for ORP4L in specific cell types $(28,29)$.

RNA sequencing of the ORP2-KO cells revealed altered expression of $>2000$ mRNAs, 579 of which displayed at least 2 -fold expression changes. IPA of the latter revealed alterations in the cellular function categories: cellular movement, cell-cell signaling and interaction, cellular development, cellular function and maintenance, cellular growth and proliferation, cell morphology, and cell death and survival. Many pathways in these categories involved the actin cytoskeleton, cell migration, adhesion or proliferation. Analysis of the ORP2 interactome uncovered 109 putative new interaction partners, IPA analysis of which revealed RhoA signaling as the most significant ORP2-associated pathway. Of the putative partners of ORP2 in RhoA signaling, SEPT9, MLC12, and ARHGAP12, as well as IQGAP1, were validated by independent pulldown or coimmunoprecipitation assays. Consistently, loss of ORP2 resulted in an abnormal F-actin morphology characterized by impaired capacity to form cortactin $^{+}$lamellipodia. Further functional analyses demonstrated that lack of ORP2 resulted in a migration defect and reduced rates of cell adhesion and proliferation.

ORP2 has been investigated in the context of cellular cholesterol and TG metabolism $(4,5,30,31)$, as well as in steroid hormone biogenesis by adrenocortical cells (8). Moreover, ORP2 has shown to localize, together with its ER membrane anchor VAP-A, at ER-LD contacts (7). Li et al. (9), in adrenocortical cells, found a physical interaction of ORP2 with DIAPH1, a Rho GTPase effector protein that coordinates cellular dynamics by regulating actin microfilament and microtubule function. The reported ORP2-DIAPH1 interaction implicated a close link between ORP2 function and the actin cytoskeleton. Connections with cytoskeletal functions have been suggested also for other members of the ORP family: ORP10 was shown to associate with microtubules and to modulate the secretion of $\beta$-lipoprotein by hepatocytes $(32,33)$. ORP1L was demonstrated to act as a sterol sensor in a protein complex that controls ER-late endosome contacts, dynein-dynactin recruitment onto late endosomes, and the microtubule-dependent motility and fusion of the 
A

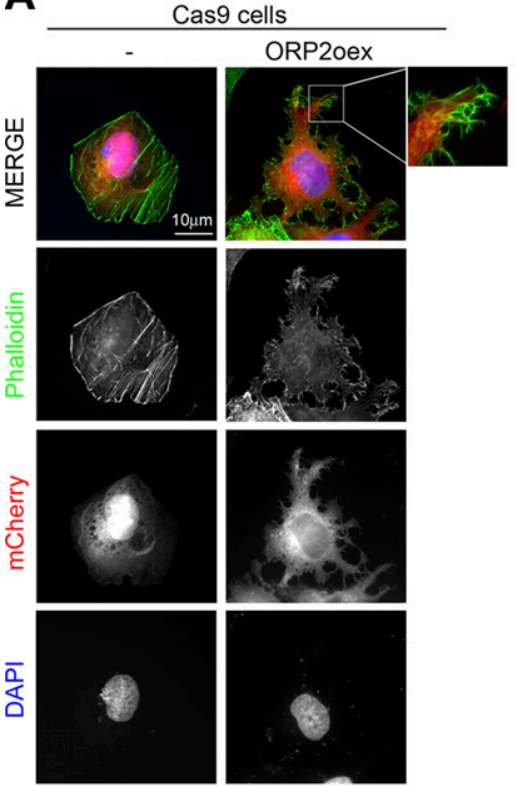

C

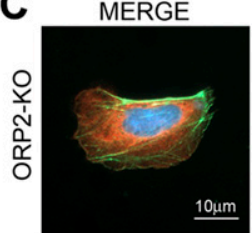

D MERGE

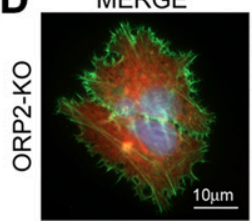

B
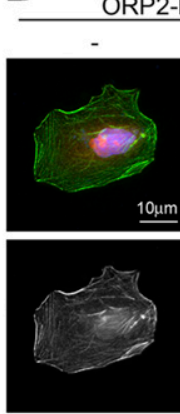

$10 \mu \mathrm{m}$
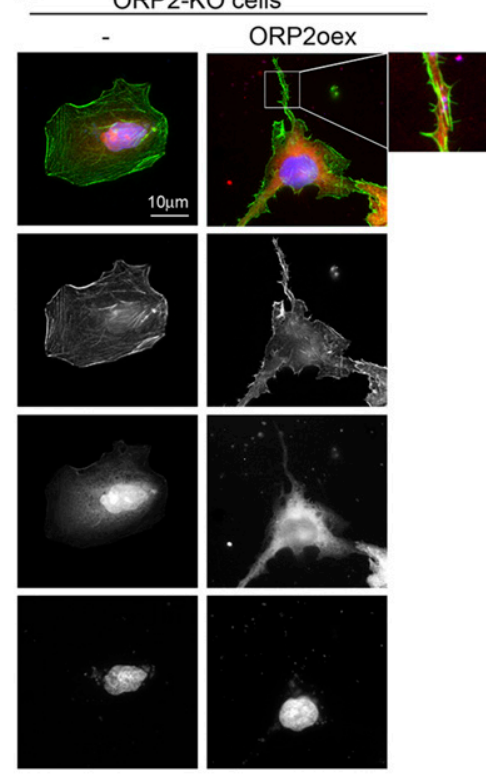

mCherry-ORP2(mPIP)
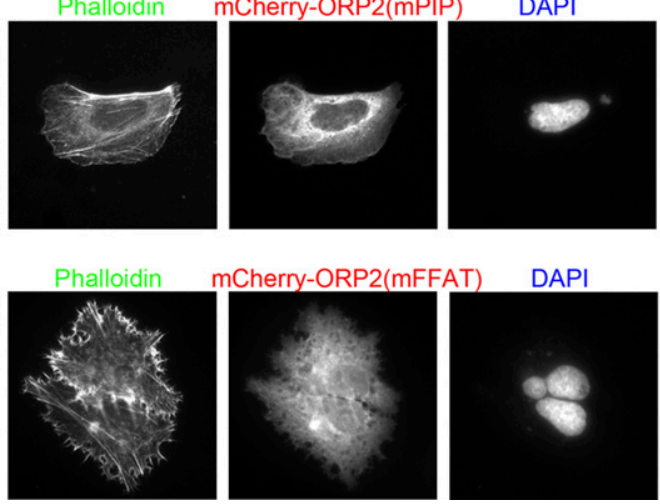

DAPI

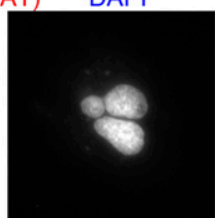

Figure 3. Reexpression of ORP2 in the $\mathrm{KO}$ cells modifies the actin cytoskeleton. $A, B$ ) Staining of F-actin with fluorescent green phalloidin in Cas9 control $(A)$ and ORP2-KO $(B)$ cells transfected with plain mCherry as a control or mCherry-ORP2. C) ORP2-KO cells transfected with mCherry-ORP2 (mPIP) with the PIP-binding cleft inactivated. D) ORP2-KO cells transfected with mCherry-ORP2 (mFFAT) incapable of binding to VAPs. endosomes $(34,35)$. Moreover, ORP3 was shown to regulate the activity of the small GTPase R-Ras, a key controller of cell adhesion and migration, and genetic manipulation of this ORP induced distinct alterations of F-actin organization $(36,37)$. Finally, ORP4 was discovered to associate with vimentin intermediate filaments and have a capacity to modify their organization $(38,39)$. Of note, Dong et al. (40) recently demonstrated that ER-endosome contacts, generated by OSBP and VAPs, regulate PI4P levels on the endosomes, thus controlling the nucleation of actin on these organelles.

The present RNA sequencing, ORP2 interactome, and morphologic analyses accumulate new evidence for a close link between the ORPs and cytoskeletal regulation. The knockout of ORP2 disrupted the F-actin organization of $\mathrm{HuH} 7$ cell and hampered cell adhesion, migration, and spreading of polarized lamellipodia. Instead of lamellipodia, the $\mathrm{KO}$ cells formed cell surface blebs, which may arise as a result of defective F-actin-plasma membrane interactions $(41,42)$. The lamellipodia and migration defects in the ORP2-KO cells provide a plausible explanation for the growth mode of the $\mathrm{KO}$ cells, as the defects may result in an inability of the dividing cells to detach from one another and migrate, thus forming islet-like cell patches upon culture. The observations outlined above indicate that ORP2 physically interacts with actin-regulatory protein machineries, but its genetic depletion also impacts the mRNA expression of such components. The physical interactions of ORP2 with actin regulators may not be mediated by ORP2-VAP complexes at the ER-LD contact sites (7), but more likely reflect ORP2 function at other subcellular locations: Laitinen et al. (4) showed by cell fractionation that $<50 \%$ of the endogenous ORP2 in Chinese hamster ovary cells was membrane-associated, and most remained in the soluble fraction. Moreover, treatment of cells with the high-affinity ligand of ORP2, 22(R) $\mathrm{OHC}$, detached ORP2 from the LD, inducing its redistribution to the plasma membrane and a diffuse cytosolic-like localization (5). Likewise, ORP2-VAP-A complexes redistributed upon addition of this oxysterol away from the ER-LD junctions (3). Interactions with membrane PIPs (30) and with actin regulators could play a role in the targeting of ORP2 to the cell cortex, where key regulation of dynamic actin polymerization, branching, and depolymerization takes place (43-45). On the other hand, several ORP family members have been reported to mediate countercurrent lipid transport employing PI4P transfer to drive the transport of sterols or phosphatidylserines (46-49). Overexpression of a mutant ORP2 


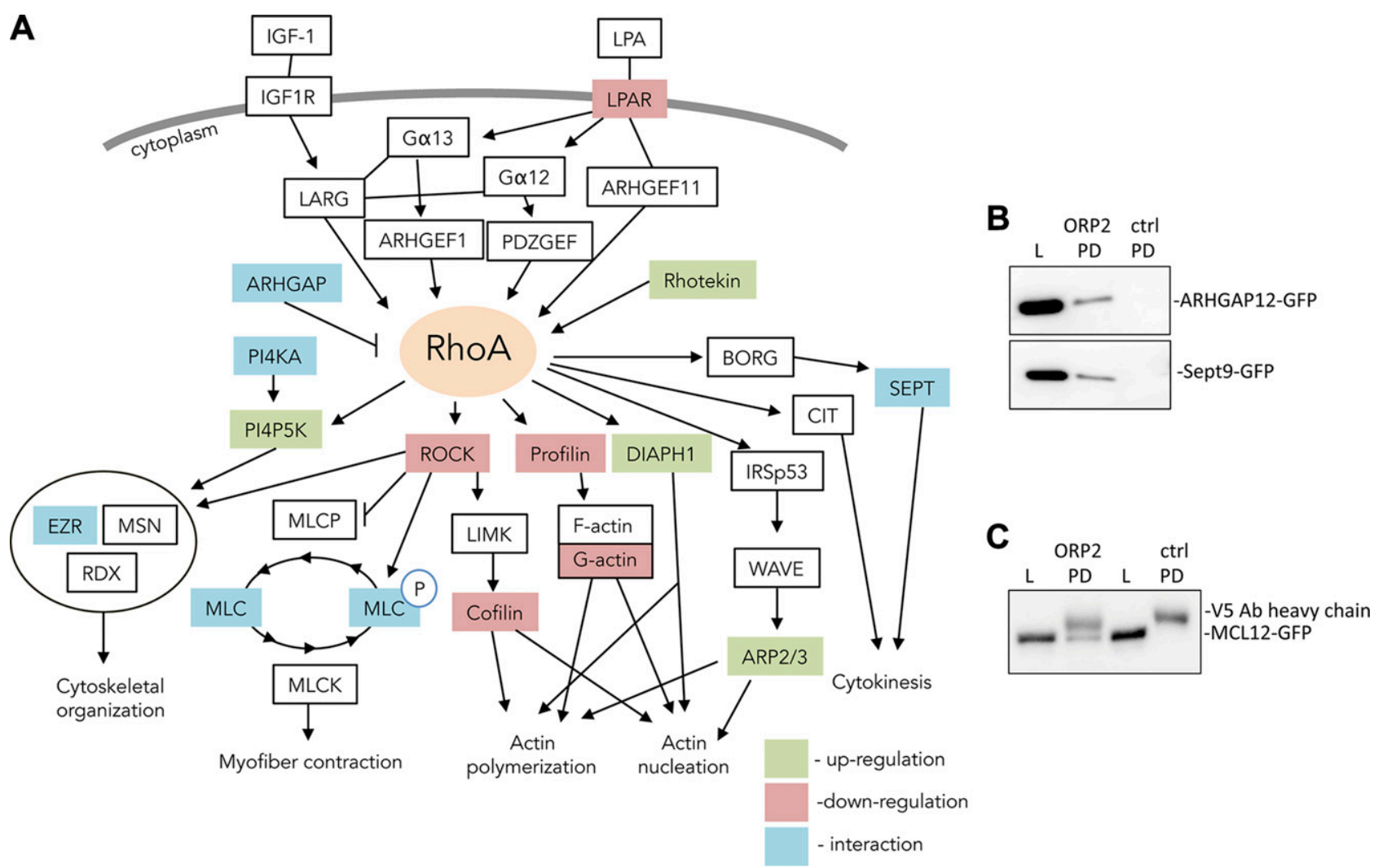

Figure 4. ORP2 interactome and ORP2-KO transcriptome analysis connects ORP2 to RhoA signaling. A) Endogenous ORP2 interaction partners were coprecipitated with anti-HA magnetic beads from HA-ORP2 overexpressing HuH7 cells and identified by mass spectrometry. The ORP2 interactome was analyzed and the results indicated that RhoA signaling was a significantly affected canonical pathway. The putative interaction partners are shown in blue. The RhoA signaling components dysregulated in the transcriptome of ORP2-KO cells are shown in green (for up-regulation) and red (for down-regulation). Most abbreviations are defined on the title page. The remaining ones follow: SEPT, septin; EZR, ezrin; PI4KA, phosphatidylinositol 4-kinase $\alpha$; PI4P5K, phosphatidylinositol-4-phosphate 5-kinase; LPAR, lysophosphatidic acid receptor; B) Pulldown assays verifying the interaction of ORP2 with ARHGAP12 and SEPT9. HuH7 cells expressing GFP-ARHGAP12 and GFP-SEPT9 constructs were lysed and subjected to GST-ORP2 pulldown. Cell lysates (L) and pulldowns (PD) were analyzed by Western blot analysis with anti-GFP antibody. Plain GST was used as a negative control. C) Coimmunoprecipitation assay verifying the interaction of ORP2 with MLC12. HuH7 cells expressing GFP-MLC12 and V5-ORP2 or, as a negative control, only the GFP-MLC12 construct, were lysed and subjected to V5-immunoprecipitation. Cell lysates (L) and coimmunoprecipitation (PD) were analyzed by Western blot analysis with anti-GFP antibody.

(mPIP) with the PIP-binding cleft inactivated failed to induce plasma membrane ruffles and cell surface protrusions like the wild-type protein. Likewise, this mutant was unable to rescue the migration defect of ORP2-KO cells. These observations suggest that the actin regulatory and cell migration functions of ORP2 may involve a lipid countertransport activity in which PIPs represent one of the substrates. Paradoxically, however, these activities of ORP2 do not appear to require its association with the VAPs, because ORP2 (mFFAT), incapable of VAP interaction, behaved similarly to the wild-type protein in the morphologic and migration assays.

The small GTPase RhoA is a major regulator of cell shape, polarity, and locomotion via actin polymerization, actomyosin contractility, cell adhesion, and microtubule dynamics (50). Signaling pathways regulated by RhoA connect PM receptors to the formation of focal adhesions and a subsequent activation of actin stress fibers (51). Among the components mediating the stimulation of actin polymerization by RhoA are the diaphanous-related formins, including DIAPH1 (9). ROCK induces actomyosin-based contractility and controls the activity of myosins and other actin-binding proteins, to facilitate the detachment and migration of cells. Moreover, RhoA plays a pivotal role in cell cycle progression, through regulation of the expression of cyclin D1 $(52,53)$ and the cyclin-dependent kinase inhibitor p27Kip1 $(54,55)$.

Both the RNA sequencing of ORP2-KO cells and the ORP2 interactome analysis supported the notion that ORP2 is physically and functionally linked to the RhoA signaling pathway. These observations bear marked resemblance to observations in yeast: The yeast ORPs, the Osh proteins, are required for polarized exocytosis by maintaining the proper localization of septins, the Rho GTPases Cdc42p and Rho1p, as well as of the Rab GTPase Sec4p (56). Moreover, the yeast ORP Osh4p was found to reside on exocytic vesicles and to form physical complexes with Cdc42p, Rho1p, Sec4p, and the exocyst subunit Sec6p (57). Physical, albeit not necessarily direct, interaction of ORP2 with the RhoA signaling components Septin 9, MLC12, and ARHGAP12 was validated. ARHGAP12 belongs to the RhoGAP family of GTPase-activating 

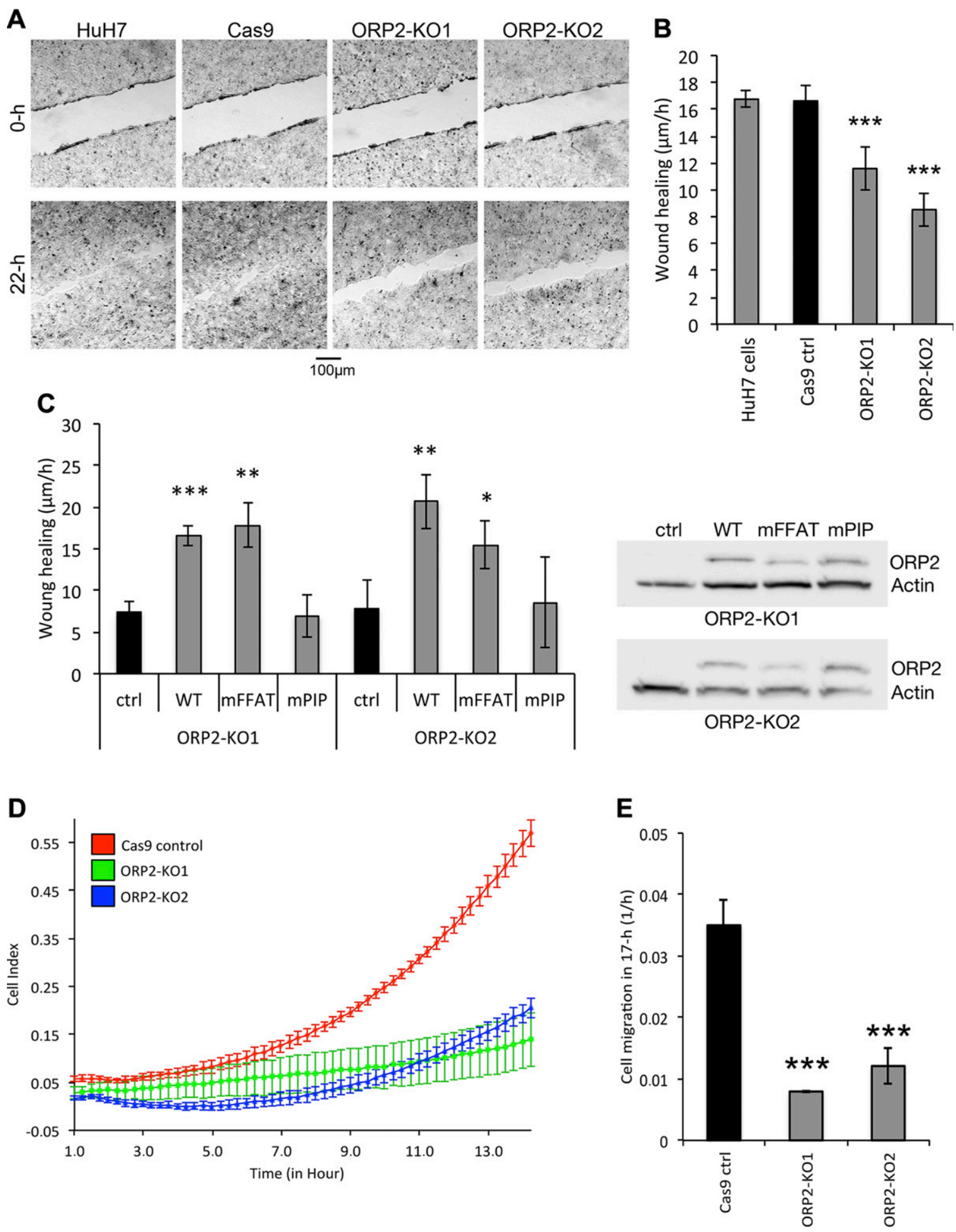

Figure 5. ORP2-KO impairs the migration of HuH7 cells. A) Wound-healing assay with HuH7, Cas9 control, and ORP2-KO1 and -KO2 cells. Representative images from the 0 to $22 \mathrm{~h}$ time points are shown. $B$ ) Quantification of the mean cell migration rate from 8 repeats of the experiment is shown. C) Quantification of the mean cell migration rate from a duplicate wound-healing experiment of ORP2KO cells infected with a empty GFP-expressing control LV (ctrl) or a LV overexpressing ORP2 wild-type (WT), or ORP2 incapable of binding to VAPs (mFFAT) or ORP2 with the PIP-binding cleft inactivated (mPIP). Western blots with anti-ORP2 verifying expression of the LV constructs, with actin as a loading control, are shown on the right. D) Migration of Cas9 control and ORP2-KO1 and -2 cells analyzed in 4 replicate assays. E) Quantification of the slope of the migration curve between 1 and $16 \mathrm{~h}$, from 2 independent experiments, each performed in quadruplicate. Data are means \pm SD. $* P<0.05, * * P<0.01, * * * P<0.001$.

proteins, which regulate the activity of Cdc42, Rac1, and RhoA Rho GTPases $(58,59)$. Septin 9 is a filament-forming GTPase suggested to act as a negative upstream regulator of RhoA, with functions in cytokinesis and cell cycle control as a possible tumor suppressor (60-62). Furthermore, MLC phosphorylation controls actin-myosin interaction 

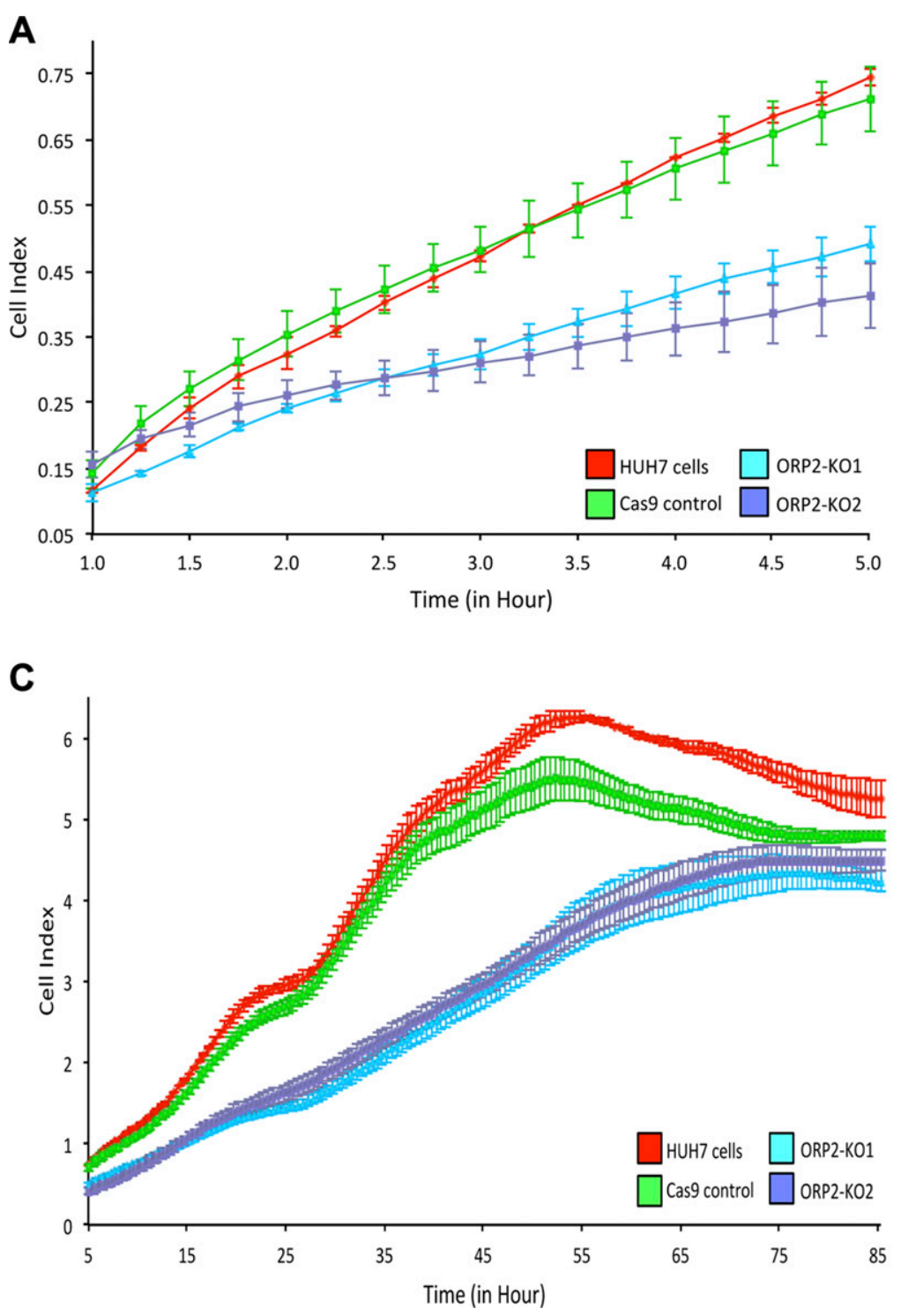

B

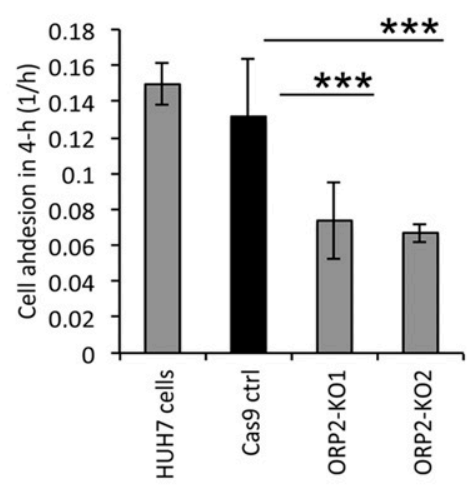

D

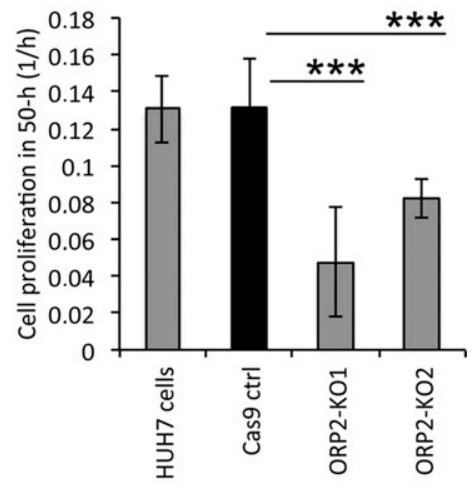

Figure 6. ORP2-KO impairs the adhesion and proliferation of $\mathrm{HuH} 7$ cells. A) Adhesion of native HuH7, Cas9 control, and ORP2KO1 and -2 cells analyzed with in 4 replicate assays. B) Quantification of the slope of the cell adhesion curve between 1 and 5 h, from 2 independent experiments, each performed in quadruplicate. C) Proliferation of native HuH7, Cas9 control, and ORP2KO1 and -2 cells analyzed in 4 replicate experiments. $D$ ) Quantification of the slope of the proliferation curve between 5 and $50 \mathrm{~h}$, from 2 independent experiments each performed in quadruplicate. Data are means \pm SD. $* * * P<0.001$.

and smooth muscle contraction, which is regulated by RhoA downstream effector ROCK (63). Most of the RhoA pathway components were down-regulated in the gene expression analysis, suggesting that loss of ORP2 dampens the signaling, or in other words, that the endogenous ORP2 acts to promote the RhoA signaling. The migration, adhesion, and proliferation assays all revealed dampening of these processes in the ORP2-KO cells, fully consistent with a reduced RhoA pathway activity. In addition to the RhoA pathway components, the RNA sequencing and interactome analyses identified several components of other actin-associated IPA pathways; from these proteins, interaction with endogenous cellular IQGAP1 was validated. IQGAP1 is a scaffold that integrates signals regulating cell adhesion, actin cytoskeleton, and the cell cycle (64). The significant impacts of ORP2 knockdown on hepatocellular migration and proliferation bring up the idea that enhanced ORP2 expression, such as that observed in chromophore kidney cancer, may contribute to malignant cell phenotypes.

We find it likely that the present observations relate to the localization of ORP2 in the stereocilia of cochlear cells and the documented role of its mutations in autosomal dominant nonsyndromic hearing loss $(11,12)$. Our data suggest that the function of ORP2 involves regulation of F-actin, which forms a key structural element of stereocilia (65). Consistently, mutations in DIAPH1, a physical interaction partner of ORP2 and a regulator of actin dynamics, were identified as a cause of similar nonsyndromic hearing loss (66-68).

To summarize, the present results indicate novel functions of ORP2 beyond lipid metabolism, as a regulator of the actin cytoskeleton with impacts on hepatocellular migration, adhesion, and proliferation. 


\section{ACKNOWLEDGMENTS}

The authors thank Eeva Jääskeläinen and Riikka Kosonen (Minerva Foundation Institute for Medical Research, Helsinki, Finland) for expert technical assistance; Sarah Edkins and Kevin Ashelford (Wales Gene Park, Cardiff, United Kingdom) for technical support; the Advanced Computing Research Team (Cardiff University) for high-throughput computer support; BioMediTech Protein Technologies core facility, a member of Biocenter Finland and Instruct-FI, the Helsinki University Genome Biology Unit, and the Biomedicum Functional Genomics Unit (HiLIFE Institute, Helsinki, Finland) for the use of the facilities and expertise. Dr. Shiqian Li (University of Helsinki) is thanked for kindly providing the CRISPR-Cas9 vectors. This study was supported by the Academy of Finland (Grant 285223; to V.M.O.); by the University of Helsinki Doctoral Programme in Biomedicine, the Finnish Concordia Fund, the Ida Montin Foundation; the FinnishNorwegian Medical Foundation, and the Aarne Koskelo Foundation (to H.K.); the Sigrid Juselius Foundation, the Magnus Ehrnrooth Foundation, and the Finnish Foundation for Cardiovascular Research (to V.M.O.); and Systems Immunity Research Institute Seedcorn Funding (to Y.Z.). The authors declare no conflicts of interest.

\section{AUTHOR CONTRIBUTIONS}

H. Kentala, A. Koponen, A. M. Kivelä, C. Li, and Y. Zhou performed the research and analyzed the data; R. Andrews analyzed the data; V. M. Olkkonen designed the research together with H. Kentala and A. M. Kivelä; and H. Kentala and V. M. Olkkonen wrote the paper.

\section{REFERENCES}

1. Ngo, M. H., Colbourne, T. R., and Ridgway, N. D. (2010) Functional implications of sterol transport by the oxysterol-binding protein gene family. Biochem. J. 429, 13-24

2. Raychaudhuri, S., and Prinz, W. A. (2010) The diverse functions of oxysterol-binding proteins. Annu. Rev. Cell Dev. Biol. 26, 157-177

3. Kentala, H., Pfisterer, S. G., Olkkonen, V. M., and Weber-Boyvat, M. (2015) Sterol liganding of OSBP-related proteins (ORPs) regulates the subcellular distribution of ORP-VAPA complexes and their impacts on organelle structure. Steroids 99, 248-258

4. Laitinen, S., Lehto, M., Lehtonen, S., Hyvärinen, K., Heino, S., Lehtonen, E., Ehnholm, C., Ikonen, E., and Olkkonen, V. M. (2002) ORP2, a homolog of oxysterol binding protein, regulates cellular cholesterol metabolism. J. Lipid Res. 43, 245-255

5. Hynynen, R., Suchanek, M., Spandl, J., Bäck, N., Thiele, C., and Olkkonen, V. M. (2009) OSBP-related protein 2 is a sterol receptor on lipid droplets that regulates the metabolism of neutral lipids. J. Lipid Res. 50, 1305-1315

6. Suchanek, M., Hynynen, R., Wohlfahrt, G., Lehto, M., Johansson, M., Saarinen, H., Radzikowska, A., Thiele, C., and Olkkonen, V. M. (2007) The mammalian oxysterol-binding protein-related proteins (ORPs) bind 25-hydroxycholesterol in an evolutionarily conserved pocket. Biochem. J. 405, 473-480

7. Weber-Boyvat, M., Kentala, H., Peränen, J., and Olkkonen, V. M. (2015) Ligand-dependent localization and function of ORPVAP complexes at membrane contact sites. Cell. Mol. Life Sci. 72, 1967-1987

8. Escajadillo, T., Wang, H., Li, L., Li, D., and Sewer, M. B. (2016) Oxysterol-related-binding-protein related protein-2 (ORP2) regulates cortisol biosynthesis and cholesterol homeostasis. Mol. Cell. Endocrinol. 427, 73-85

9. Li, D., Dammer, E. B., Lucki, N. C., and Sewer, M. B. (2013) cAMPstimulated phosphorylation of diaphanous 1 regulates protein stability and interaction with binding partners in adrenocortical cells. Mol. Biol. Cell 24, 848-857
10. Sewer, M. B., and Li, D. (2013) Regulation of adrenocortical steroid hormone production by RhoA-diaphanous 1 signaling and the cytoskeleton. Mol. Cell. Endocrinol. 371, 79-86

11. Thoenes, M., Zimmermann, U., Ebermann, I., Ptok, M., Lewis, M. A., Thiele, H., Morlot, S., Hess, M. M., Gal, A., Eisenberger, T., Bergmann, C., Nurnberg, G., Nurnberg, P., Steel, K. P., Knipper, M., and Bolz, H. J. (2015) OSBPL2 encodes a protein of inner and outer hair cell stereocilia and is mutated in autosomal dominant hearing loss (DFNA67). Orphanet J. Rare Dis. 10, 15

12. Xing, G., Yao, J., Wu, B., Liu, T., Wei, Q., Liu, C., Lu, Y., Chen, Z., Zheng, H., Yang, X., and Cao, X. (2015) Identification of OSBPL2 as a novel candidate gene for progressive nonsyndromic hearing loss by whole-exome sequencing. Genet. Med. 17, 210-218

13. Ran, F. A., Hsu, P. D., Wright, J., Agarwala, V., Scott, D. A., and Zhang, F. (2013) Genome engineering using the CRISPR-Cas9 system. Nat. Protoc. 8, 2281-2308

14. Salo, V. T., Belevich, I., Li, S., Karhinen, L., Vihinen, H., Vigouroux, C., Magré, J., Thiele, C., Hölttä-Vuori, M., Jokitalo, E., and Ikonen, E. (2016) Seipin regulates ER-lipid droplet contacts and cargo delivery. EMBO J. 35, 2699-2716

15. Nakabayashi, H., Taketa, K., Miyano, K., Yamane, T., and Sato, J. (1982) Growth of human hepatoma cells lines with differentiated functions in chemically defined medium. Cancer Res. 42 , $3858-3863$

16. Li, H., and Durbin, R. (2009) Fast and accurate short read alignment with Burrows-Wheeler transform. Bioinformatics 25, 1754-1760

17. Liao, Y., Smyth, G. K., and Shi, W. (2014) FeatureCounts: an efficient general purpose program for assigning sequence reads to genomic features. Bioinformatics 30, 923-930

18. Love, M. I., Huber, W., and Anders, S. (2014) Moderated estimation of fold change and dispersion for RNA-seq data with DESeq2. Genome Biol. 15, 550

19. Gesmann, M., and de Castillo, D. (2011) Using the Google visualisation API with R. RJ. 3, 40-44

20. Béaslas, O., Vihervaara, T., Li, J., Laurila, P. P., Yan, D., and Olkkonen, V. M. (2012) Silencing of OSBP-related protein 8 (ORP8) modifies the macrophage transcriptome, nucleoporin p62 distribution, and migration capacity. Exp. Cell Res. 318, 1933-1945

21. Ryberg, E., Larsson, N., Sjögren, S., Hjorth, S., Hermansson, N. O., Leonova, J., Elebring, T., Nilsson, K., Drmota, T., and Greasley, P. J. (2007) The orphan receptor GPR55 is a novel cannabinoid receptor. Br. J. Pharmacol. 152, 1092-1101

22. Chung Moh, M., Hoon Lee, L., and Shen, S. (2005) Cloning and characterization of hepaCAM, a novel Ig-like cell adhesion molecule suppressed in human hepatocellular carcinoma. J. Hepatol. 42, 833-841

23. Wight, T. N., Kinsella, M. G., Evanko, S. P., Potter-Perigo, S., and Merrilees, M.J. (2014) Versican and the regulation of cell phenotype in disease. Biochim. Biophys. Acta 1840, 2441-2451

24. Beh, C. T., Cool, L., Phillips, J., and Rine, J. (2001) Overlapping functions of the yeast oxysterol-binding protein homologues. Genetics 157, 1117-1140

25. Olkkonen, V. M., and Li, S. (2013) Oxysterol-binding proteins: sterol and phosphoinositide sensors coordinating transport, signaling and metabolism. Prog. Lipid Res. 52, 529-538

26. McCarty, O. J., Larson, M. K., Auger, J. M., Kalia, N., Atkinson, B. T., Pearce, A. C., Ruf, S., Henderson, R. B., Tybulewicz, V. L., Machesky, L. M., and Watson, S. P. (2005) Rac1 is essential for platelet lamellipodia formation and aggregate stability under flow. J. Biol. Chem. 280, 39474-39484

27. Waterman-Storer, C. M., Worthylake, R. A., Liu, B. P., Burridge, K., and Salmon, E. D. (1999) Microtubule growth activates Rac1 to promote lamellipodial protrusion in fibroblasts. Nat. Cell Biol. $1,45-50$

28. Charman, M., Colbourne, T. R., Pietrangelo, A., Kreplak, L., and Ridgway, N. D. (2014) Oxysterol-binding protein (OSBP)-related protein 4 (ORP4) is essential for cell proliferation and survival. J. Biol. Chem. 289, 15705-15717

29. Zhong, W., Yi, Q., Xu, B., Li, S., Wang, T., Liu, F., Zhu, B., Hoffmann, P. R., Ji, G., Lei, P., Li, G., Li, J., Li, J., Olkkonen, V. M., and Yan, D. (2016) ORP4L is essential for T-cell acute lymphoblastic leukemia cell survival. Nat. Commun. 7, 12702

30. Hynynen, R., Laitinen, S., Käkelä, R., Tanhuanpää, K., Lusa, S., Ehnholm, C., Somerharju, P., Ikonen, E., and Olkkonen, V. M. (2005) Overexpression of OSBP-related protein 2 (ORP2) induces changes in cellular cholesterol metabolism and enhances endocytosis. Biochem. J. 390, 273-283 
31. Jansen, M., Ohsaki, Y., Rega, L. R., Bittman, R., Olkkonen, V. M., and Ikonen, E. (2011) Role of ORPs in sterol transport from plasma membrane to ER and lipid droplets in mammalian cells. Traffic $\mathbf{1 2}$, 218-231

32. Perttilä, J., Merikanto, K., Naukkarinen, J., Surakka, I., Martin, N. W., Tanhuanpää, K., Grimard, V., Taskinen, M. R., Thiele, C., Salomaa, V., Jula, A., Perola, M., Virtanen, I., Peltonen, L., and Olkkonen, V. M. (2009) OSBPL10, a novel candidate gene for high triglyceride trait in dyslipidemic Finnish subjects, regulates cellular lipid metabolism. J. Mol. Med. (Berl.) 87, 825-835

33. Nissilä, E., Ohsaki, Y., Weber-Boyvat, M., Perttilä, J., Ikonen, E., and Olkkonen, V. M. (2012) ORP10, a cholesterol binding protein associated with microtubules, regulates apolipoprotein B-100 secretion. Biochim. Biophys. Acta 1821, 1472-1484

34. Johansson, M., Rocha, N., Zwart, W., Jordens, I., Janssen, L., Kuijl, C., Olkkonen, V. M., and Neefjes, J. (2007) Activation of endosomal dynein motors by stepwise assembly of Rab7-RILPp150Glued, ORP1L, and the receptor betalll spectrin. J. Cell Biol. 176, 459-471

35. Rocha, N., Kuijl, C., van der Kant, R., Janssen, L., Houben, D., Janssen, H., Zwart, W., and Neefjes, J. (2009) Cholesterol sensor ORP1L contacts the ER protein VAP to control Rab7-RILP-p150 Glued and late endosome positioning. J. Cell Biol. 185, 1209-1225

36. Lehto, M., Mäyränpää, M. I., Pellinen, T., Ihalmo, P., Lehtonen, S., Kovanen, P. T., Groop, P. H., Ivaska, J., and Olkkonen, V. M. (2008) The R-Ras interaction partner ORP3 regulates cell adhesion. J. Cell Sci. 121, 695-705

37. Weber-Boyvat, M., Kentala, H., Lilja, J., Vihervaara, T., Hanninen, R., Zhou, Y., Peränen, J., Nyman, T. A., Ivaska, J., and Olkkonen, V. M. (2015) OSBP-related protein 3 (ORP3) coupling with VAMP-associated protein A regulates R-Ras activity. Exp. Cell Res. 331, 278-291

38. Wang, C., JeBailey, L., and Ridgway, N. D. (2002) Oxysterol-bindingprotein (OSBP)-related protein 4 binds 25-hydroxycholesterol and interacts with vimentin intermediate filaments. Biochem. J. 361, 461-472

39. Wyles, J. P., Perry, R. J., and Ridgway, N. D. (2007) Characterization of the sterol-binding domain of oxysterol-binding protein (OSBP)related protein 4 reveals a novel role in vimentin organization. Exp. Cell Res. 313, 1426-1437

40. Dong, R., Saheki, Y., Swarup, S., Lucast, L., Harper, J. W., and De Camilli, P. (2016) Endosome-ER contacts control actin nucleation and retromer function through VAP-dependent regulation of PI4P. Cell 166, 408-423

41. Charras, G. T., Hu, C. K., Coughlin, M., and Mitchison, T. J. (2006) Reassembly of contractile actin cortex in cell blebs. J. Cell Biol. 175, $477-490$

42. Aoki, K., Maeda, F., Nagasako, T., Mochizuki, Y., Uchida, S., and Ikenouchi, J. (2016) A RhoA and Rnd3 cycle regulates actin reassembly during membrane blebbing. Proc. Natl. Acad. Sci. USA 113, E1863-E1871

43. Zhang, L., Mao, Y. S., Janmey, P. A., and Yin, H. L. (2012) Phosphatidylinositol 4, 5 bisphosphate and the actin cytoskeleton. Subcell. Biochem. 59, 177-215

44. Tan,J., and Brill,J. A. (2014) Cinderella story: PI4P goes from precursor to key signaling molecule. Crit. Rev. Biochem. Mol. Biol. 49, 33-58

45. Choi, S., Thapa, N., Tan, X., Hedman, A. C., and Anderson, R. A. (2015) PIP kinases define PI4,5 $\mathrm{P}_{2}$ signaling specificity by association with effectors. Biochim. Biophys. Acta 1851, 711-723

46. De Saint-Jean, M., Delfosse, V., Douguet, D., Chicanne, G., Payrastre, B., Bourguet, W., Antonny, B., and Drin, G. (2011) Osh4p exchanges sterols for phosphatidylinositol 4-phosphate between lipid bilayers. J. Cell Biol. 195, 965-978

47. Mesmin, B., Bigay, J., Moser von Filseck, J., Lacas-Gervais, S., Drin, G., and Antonny, B. (2013) A four-step cycle driven by PI(4)P hydrolysis directs sterol/PI(4)P exchange by the ER-Golgi tether OSBP. Cell 155, 830-843

48. Moser von Filseck, J., Vanni, S., Mesmin, B., Antonny, B., and Drin, G. (2015) A phosphatidylinositol-4-phosphate powered exchange mechanism to create a lipid gradient between membranes. Nat. Commun. 6, 6671

49. Chung, J., Torta, F., Masai, K., Lucast, L., Czapla, H., Tanner, L. B., Narayanaswamy, P., Wenk, M. R., Nakatsu, F., and De Camilli, P. (2015) INTRACELLULAR TRANSPORT. PI4P/phosphatidylserine countertransport at ORP5- and ORP8-mediated ER-plasma membrane contacts. Science $\mathbf{3 4 9}, 428-432$

50. Sackmann, E. (2015) How actin/myosin crosstalks guide the adhesion, locomotion and polarization of cells. Biochim. Biophys. Acta 1853, 3132-3142
51. Burridge, K., and Guilluy, C. (2016) Focal adhesions, stress fibers and mechanical tension. Exp. Cell Res. 343, 14-20

52. Croft, D. R., and Olson, M. F. (2006) The Rho GTPase effector ROCK regulates cyclin A, cyclin D1, and p27Kip1 levels by distinct mechanisms. Mol. Cell. Biol. 26, 4612-4627

53. Pedraza, N., Cemeli, T., Monserrat, M. V., Garí, E., and Ferrezuelo, F. (2017) Regulation of small GTPase activity by G1 cyclins [E-pub ahead of print]. Small GTPases 10.1080/21541248.2016.1268665

54. Larrea, M. D., Hong, F., Wander, S. A., da Silva, T. G., Helfman, D., Lannigan, D., Smith, J. A., and Slingerland, J. M. (2009) RSK1 drives p27Kip1 phosphorylation at T198 to promote RhoA inhibition and increase cell motility. Proc. Natl. Acad. Sci. USA 106, 9268-9273

55. Kim, H., Kang, M., Lee, S. A., Kwak, T. K., Jung, O., Lee, H. J., Kim, S. H., and Lee, J. W. (2010) TM4SF5 accelerates G1/S phase progression via cytosolic p27Kipl expression and RhoA activity. Biochim. Biophys. Acta 1803, 975-982

56. Kozminski, K. G., Alfaro, G., Dighe, S., and Beh, C. T. (2006) Homologues of oxysterol-binding proteins affect Cdc42p-and Rholpmediated cell polarization in Saccharomyces cerevisiae. Traffic 7, 1224-1242

57. Alfaro, G., Johansen, J., Dighe, S. A., Duamel, G., Kozminski, K. G., and Beh, C. T. (2011) The sterol-binding protein Kes1/Osh4p is a regulator of polarized exocytosis. Traffic 12, 1521-1536

58. Lazarini, M., Traina, F., Machado-Neto, J. A., Barcellos, K. S., Moreira, Y. B., Brandão, M. M., Verjovski-Almeida, S., Ridley, A. J., and Saad, S. T. (2013) ARHGAP21 is a RhoGAP for RhoA and RhoC with a role in proliferation and migration of prostate adenocarcinoma cells. Biochim. Biophys. Acta 1832, 365-374

59. Bishop, A. L., and Hall, A. (2000) Rho GTPases and their effector proteins. Biochem. J. 348, 241-255

60. Nagata, K., and Inagaki, M. (2005) Cytoskeletal modification of Rho guanine nucleotide exchange factor activity: identification of a Rho guanine nucleotide exchange factor as a binding partner for Sept $9 \mathrm{~b}$, a mammalian septin. Oncogene 24, 65-76

61. Burrows, J. F., Chanduloy, S., McIlhatton, M. A., Nagar, H., Yeates, K. Donaghy, P., Price, J., Godwin, A. K., Johnston, P. G., and Russell, S. E. (2003) Altered expression of the septin gene, SEPT9, in ovarian neoplasia. J. Pathol. 201, 581-588

62. Kalikin, L. M., Sims, H. L., and Petty, E. M. (2000) Genomic and expression analyses of alternatively spliced transcripts of the MLL septin-like fusion gene (MSF) that map to a $17 \mathrm{q} 25$ region of loss in breast and ovarian tumors. Genomics 63, 165-172

63. Amano, M., Ito, M., Kimura, K., Fukata, Y., Chihara, K., Nakano, T. Matsuura, Y., and Kaibuchi, K. (1996) Phosphorylation and activation of myosin by Rho-associated kinase (Rho-kinase). J. Biol. Chem. 271, 20246-20249

64. Briggs, M. W., and Sacks, D. B. (2003) IQGAP proteins are integral components of cytoskeletal regulation. EMBO Rep. 4, 571-574

65. McGrath, J., Roy, P., and Perrin, B. J. (2017) Stereocilia morphogenesis and maintenance through regulation of actin stability. Semin. Cell Dev. Biol. 65, 88-95

66. Kang, T. H., Baek, J. I., Sagong, B., Park, H.J., Park, C. I., Lee, K. Y., and Kim, U. K. (2017) A novel missense variant in the DIAPH1 gene in a Korean family with autosomal dominant nonsyndromic hearing loss. Genes Genet. Syst. 91, 289-292

67. Neuhaus, C., Lang-Roth, R., Zimmermann, U., Heller, R., Eisenberger, T., Weikert, M., Markus, S., Knipper, M., and Bolz, H. J. (2017) Extension of the clinical and molecular phenotype of DIAPH1-associated autosomal dominant hearing loss (DFNA1). Clin. Genet. 91, 892-901

68. Stritt, S., Nurden, P., Turro, E., Greene, D., Jansen, S. B., Westbury, S. K., Petersen, R., Astle, W. J., Marlin, S., Bariana, T. K., Kostadima, M., Lentaigne, C., Maiwald, S., Papadia, S., Kelly, A. M., Stephens, J. C., Penkett, C. J., Ashford, S., Tuna, S., Austin, S., Bakchoul, T., Collins, P., Favier, R., Lambert, M. P., Mathias, M., Millar, C. M., Mapeta, R., Perry, D. J., Schulman, S., Simeoni, I., Thys, C., Gomez, K., Erber, W. N., Stirrups, K., Rendon, A., Bradley, J. R., van Geet, C., Raymond, F. L., Laffan, M. A., Nurden, A. T., Nieswandt, B., Richardson, S., Freson, K., Ouwehand, W. H., and Mumford, A. D.; BRIDGE-BPD Consortium. (2016) A gain-of-function variant in DIAPH1 causes dominant macrothrombocytopenia and hearing loss. Blood 127, 2903-2914

69. Yamanaka, H., Maehira, F., Oshiro, M., Asato, T., Yanagawa, Y., Takei, H., and Nakashima, Y. (2000) A possible interaction of thioredoxin with VDUP1 in HeLa cells detected in a yeast two-hybrid system. Biochem. Biophys. Res. Commun. 271, 796-800 
70. Chutkow, W. A., Patwari, P., Yoshioka, J., and Lee, R. T. (2008) Thioredoxin-interacting protein (Txnip) is a critical regulator of hepatic glucose production. J. Biol. Chem. 283, 2397-2406

71. Kuroda, S., Oyasu, M., Kawakami, M., Kanayama, N., Tanizawa, K., Saito, N., Abe, T., Matsuhashi, S., and Ting, K. (1999) Biochemical characterization and expression analysis of neural thrombospondin1-like proteins NELL1 and NELL2. Biochem. Biophys. Res. Commun. 265, 79-86

72. Shathasivam, P., Kollara, A., Spybey, T., Park, S., Clarke, B., Ringuette, M. J., and Brown, T. J. (2017) VEPH1 expression decreases vascularisation in ovarian cancer xenografts and inhibits VEGFA and IL8 expression through inhibition of AKT activation. Br. J. Cancer 116, 1065-1076

73. Anderson, G. J., Frazer, D. M., McKie, A. T., Wilkins, S. J., and Vulpe, C. D. (2002) The expression and regulation of the iron transport molecules hephaestin and IREG1: implications for the control of iron export from the small intestine. Cell Biochem. Biophys. 36, 137-146

74. Noma, N., Simizu, S., Kambayashi, Y., Kabe, Y., Suematsu, M., and Umezawa, K. (2012) Involvement of NF-кB-mediated expression of galectin-3-binding protein in TNF- $\alpha$-induced breast cancer cell adhesion. Oncol. Rep. 27, 2080-2084

75. Tashian, R. E. (1989) The carbonic anhydrases: widening perspectives on their evolution, expression and function. BioEssays 10, 186-192

76. Blom, A. M., Villoutreix, B. O., and Dahlbäck, B. (2004) Complement inhibitor C4b-binding protein-friend or foe in the innate immune system? Mol. Immunol. 40, 1333-1346

77. Faugaret, D., Chouinard, F. C., Harbour, D., El Azreq, M. A., and Bourgoin, S. G. (2011) An essential role for phospholipase D in the recruitment of vesicle amine transport protein-1 to membranes in human neutrophils. Biochem. Pharmacol. 81, 144-156
78. Schürpf, T., Chen, Q., Liu, J. H., Wang, R., Springer, T. A., and Wang, J. H. (2012) The RGD finger of Del-1 is a unique structural feature critical for integrin binding. FASEB J. 26, 3412-3420

79. Christianson, J. C., Olzmann, J. A., Shaler, T. A., Sowa, M. E., Bennett, E. J., Richter, C. M., Tyler, R. E., Greenblatt, E. J., Harper, J. W., and Kopito, R. R. (2011) Defining human ERAD networks through an integrative mapping strategy. Nat. Cell Biol. 14, 93-105

80. O'Brien, R. J., Xu, D., Petralia, R. S., Steward, O., Huganir, R. L., and Worley, P. (1999) Synaptic clustering of AMPA receptors by the extracellular immediate-early gene product Narp. Neuron 23, 309-323

81. Wilson, C. A., Tsuchida, M. A., Allen, G. M., Barnhart, E. L., Applegate, K. T., Yam, P. T., Ji, L., Keren, K., Danuser, G., and Theriot, J. A. (2010) Myosin II contributes to cell-scale actin network treadmilling through network disassembly. Nature 465, 373-377

82. Castellino, F. J., and Ploplis, V.A. (2005) Structure and function of the plasminogen/plasmin system. Thromb. Haemost. 93, 647-654

83. Morris, S. M., Jr. (2009) Recent advances in arginine metabolism: roles and regulation of the arginases. Br. J. Pharmacol. 157, 922-930

84. Halestrap, A. P., and Price, N. T. (1999) The proton-linked monocarboxylate transporter (MCT) family: structure, function and regulation. Biochem. J. 343, 281-299

85. Worthley, D. L., Bardy, P. G., and Mullighan, C. G. (2005) Mannosebinding lectin: biology and clinical implications. Intern. Med. J. 35, $548-555$

86. Jiang, W., and Newsham, I. F. (2006) The tumor suppressor DAL-1/4. $1 \mathrm{~B}$ and protein methylation cooperate in inducing apoptosis in $\mathrm{MCF}$ 7 breast cancer cells. Mol. Cancer $\mathbf{5}, 4$

Received for publication June 28, 2017. Accepted for publication October 23, 2017. 